\title{
Fuel Efficiency and Motor Vehicle Travel: The Declining Rebound Effect
}

Kenneth A. Small and Kurt Van Dender*

Department of Economics

University of California, Irvine

Irvine, CA 92697-5100

ksmall@uci.edu, kvandend@uci.edu

*Corresponding author. Tel: 949-824-9698; Fax 949-824-2182

UC Irvine Economics Working Paper \#05-06-03

This version: April 10, 2006 (corrected July 17, 2006 and August 18, 2007)

Shorter version published, Energy Journal, vol. 28, no. 1 (2007), pp. 25-51.

Note: the published version lacks the corrections to the bottom panel of Tables 5 and B2, described here in note 26.

\begin{abstract}
:
We estimate the rebound effect for motor vehicles, by which improved fuel efficiency causes additional travel, using a pooled cross section of US states for 1966-2001. Our model accounts for endogenous changes in fuel efficiency, distinguishes between autocorrelation and lagged effects, includes a measure of the stringency of fuel-economy standards, and allows the rebound effect to vary with income, urbanization, and the fuel cost of driving. At sample averages of variables, our simultaneous-equations estimates of the short- and long-run rebound effect are $4.5 \%$ and $22.2 \%$. But rising real income caused it to diminish substantially over the period, aided by falling fuel prices. With variables at $1997-2001$ levels, our estimates are only $2.2 \%$ and $10.7 \%$, considerably smaller than values typically assumed for policy analysis. With income at the $1997-2001$ level and fuel prices at the sample average, the estimates are $3.1 \%$ and $15.3 \%$, respectively.

JEL codes: Q0, D5, R4, C2

Keywords: carbon dioxide, fuel economy, travel demand, motor vehicle use, rebound effect

\section{Acknowledgment:}

This paper is partly based on research sponsored by the California Air Resources Board and the California Energy Commission, and has been revised with support from the University of California Energy Institute. We would like to thank S. Jun and C.K. Kim for excellent research assistance. Earlier stages of this work have benefited from comments by David Brownstone, David Greene, Winston Harrington, Eric Haxthausen, Jun Ishii, Chris Kavalec, Charles Lave, Lars Lefgren, Reza Mahdavi, Don Pickrell, and Charles Shulock, among others. We also appreciate comments at colloquia at Brigham Young University, Catholic University of Leuven, and Resources for the Future. All errors, shortcomings, and interpretations are our responsibility. Nothing in this paper has been endorsed by or represents the policy of the sponsoring organizations.
\end{abstract}




\section{Introduction}

It has long been realized that improving energy efficiency releases an economic reaction that partially offsets the original energy saving. As the energy efficiency of some process improves, the process becomes cheaper, thereby providing an incentive to increase its use. Thus total energy consumption changes less than proportionally to changes in physical energy efficiency. This "rebound effect" is typically quantified as the extent of the deviation from proportionality. It has been studied in many contexts, including residential space heating and cooling, appliances, and transportation (Greening, Greene, and Difiglio, 2000).

For motor vehicles, the process under consideration is use of fuel in producing vehiclemiles traveled (VMT). When vehicles are made more fuel-efficient, it costs less to drive a mile, so VMT increases if demand for it is downward-sloping. That in turn causes more fuel to be used than would be the case if VMT were constant; the difference is the rebound effect. Obtaining reliable measures of it is important because it helps determine the effectiveness of measures intended to reduce fuel consumption and because increased driving exacerbates congestion and air pollution. For example, the rebound effect was an issue in the evaluation of recently adopted greenhouse-gas regulations for California (CARB, 2004, Sect. 12.3-12.4). It has played a prominent role in analyses of the Corporate Average Fuel Economy (CAFE) regulations in the US and of proposals to strengthen them.

This paper presents estimates of the rebound effect for passenger-vehicle use that are based on pooled cross-sectional time-series data at the U.S. State level. It adds to a sizeable econometric literature, contributing four main improvements. First, we use a longer time series (1966-2001) than was possible in earlier studies. This increases the precision of our estimates, enabling us (among other things) to determine short- and long-run rebound effects and their dependence on income. Second, the econometric specifications rest on an explicit model of simultaneous aggregate demand for VMT, vehicle stock, and fuel efficiency. The model is estimated directly using two- and three-stage least squares (2SLS and 3SLS); thus we can treat consistently the fact that the rebound effect is defined starting with a given change in fuel efficiency, yet fuel efficiency itself is endogenous. Third, we measure the stringency of CAFE regulation, which was in effect during part of our sample period, in a theoretically motivated way: as the gap between the standard and drivers' desired aggregate fuel efficiency, the latter estimated using pre-CAFE data and a specification consistent with our behavioral model. Fourth, 
we allow the rebound effect to depend on income and on the fuel cost of driving. The dependence on income is expected from theory (Greene, 1992), and is suggested by micro-based estimates across deciles of the income distribution (West, 2004). Just like income changes, changes in fuel prices affect the share of fuel costs in the total cost of driving, and so we also expect them to influence the rebound effect.

Our best estimates of the rebound effect for the US as a whole, over the period 19662001, are $4.5 \%$ for the short run and $22.2 \%$ for the long run. The 2SLS and 3SLS results are mostly similar to each other but differ from ordinary least squares (OLS) results, which are unsatisfactory as they strongly depend on details of the specification. While our short-run estimate is at the lower end of results found in the literature, the long-run estimate is similar to what is found in most earlier work. Additional estimation results, like the long-run priceelasticity of fuel demand (-0.43) and the proportion of it that is caused by mileage changes $(52 \%)$, are similar to those in the literature.

This agreement is qualified, however, by our finding that the magnitude of the rebound effect declines with income and, with less certainty, increases with the fuel cost of driving. These dependences substantially reduce the magnitude that applies to recent years . For example, using average values of income, urbanization and fuel costs measured over the most recent five-year period covered in our data set (1997-2001), our results imply short- and long-run rebound effects of just $2.2 \%$ and $10.7 \%$, roughly half the average values over the longer time period. Similarly, the long-run price elasticity of fuel demand declines in magnitude in recent years and so does the proportion of it caused by changes in amount of motor-vehicle travel. These changes are largely the result of real income growth and lower real fuel prices. Future values of the rebound effect depend on how those factors evolve.

The structure of the paper is as follows. Section 2 introduces the definition of the rebound effect and reviews some key contributions toward measuring it. Section 3 presents our theoretical model and the econometric specification, and section 4 presents estimation results. Section 5 concludes.

\section{Background}

The rebound effect for motor vehicles is typically defined in terms of an exogenous change in fuel efficiency, $E$. Fuel consumption $F$ and motor-vehicle travel $M$ - the latter measured here as VMT per year - are related through the identity $F=M / E$. The rebound effect 
arises because travel $M$ depends (among other things) on the variable cost per mile of driving, a part of which is the per-mile fuel cost, $P_{M} \equiv P_{F} / E$, where $P_{F}$ is the price of fuel. This dependence can be measured by the elasticity of $M$ with respect to $P_{M}$, which we denote $\varepsilon_{M, P M}$. When $E$ is viewed as exogenous, it is easy to show that fuel usage responds to it according to the elasticity equation: $\varepsilon_{F, E}=-1-\varepsilon_{M, P M}$. Thus a non-zero value of $\varepsilon_{M, P M}$ means that $F$ is not inversely proportional to $E$ : it causes the absolute value of $\varepsilon_{F, E}$ to be smaller than one. For this reason, $-\varepsilon_{M, P M}$ itself is usually taken as a definition of the rebound effect.

Two of our innovations relate directly to limitations of this standard definition of the rebound effect. First, the standard definition postulates an exogenous change in fuel efficiency $E$. Yet most empirical measurements of the rebound effect rely heavily on variations in the fuel price $P_{F},{ }^{1}$ in which case it is implausible that $E$ is exogenous. This can be seen by noting the substantial differences in empirical estimates of the fuel-price elasticities of fuel consumption, $\varepsilon_{F, P F}$, and of travel, $\varepsilon_{M, P F}{ }^{2}$ As shown by USDOE (1996: 5-11), they are related by $\varepsilon_{F, P F}=$ $\varepsilon_{M, P F} \cdot\left(1-\varepsilon_{E, P F}\right)-\varepsilon_{E, P F}$, where $\varepsilon_{E, P F}$ measures the effect of fuel price on efficiency. Thus the observed difference between $\varepsilon_{F, P F}$ and $\varepsilon_{M, P F}$ requires that $\varepsilon_{E, P F}$ be considerably different from zero. Ignoring this dependence of $E$ on $P_{F}$, as is done in many studies, may cause the rebound effect to be overestimated if unobserved factors that cause $M$ to be large (e.g. an unusually long commute) also cause $E$ to be large (e.g. the commuter chooses fuel-efficient vehicles to reduce the cost of that commute).

A second limitation of the standard definition is that fuel cost is just one of several components of the total cost of using motor vehicles. Another important component is time cost, which is likely to increase as incomes grow. If consumers' response to fuel costs is related to the proportion of total cost accounted for by fuel, then $\left|\varepsilon_{M, P M}\right|$ should increase with fuel cost itself and diminish with income (Greene, 1992). Our specification allows for such dependences. Furthermore, time costs increase with traffic congestion; we account for this indirectly by allowing the rebound effect to depend on urbanization, although empirically this turns out to be

\footnotetext{
${ }^{1}$ Most studies assume that that travel responds to fuel price $P_{F}$ and efficiency $E$ with equal and opposite elasticities, as implied by the definition of the rebound effect based on the combined variable $P_{M}=P_{F} / E$. See for example Schimek (1996), Table 2 and Greene et al. (1999), fn. 6.

${ }^{2}$ See USDOE (1996, pp. 5-14 and 5-83 to 5-87); Graham and Glaister (2002, p. 17); and the review in Parry and Small (2005).
} 
unimportant. An extension, not attempted here, would be to allow congestion to be endogenous within the system that determines amount of travel.

Some empirical studies of the rebound effect have used aggregate time-series data. Greene (1992) uses annual U.S. data for 1957-1989 to estimate the rebound effect at 5 to $15 \%$ both in the short and long run, with a best estimate of $12.7 \%$. According to Greene, failing to account for autocorrelation - which he estimates at 0.74 - results in spurious measurements of lagged values and to the erroneous conclusion that long-run effects are larger than short-run effects. ${ }^{3}$ Greene also presents evidence that the fuel-cost-per-mile elasticity declines over time, consistent with the effect of income just discussed; but the evidence has only marginal statistical significance.

Jones (1993) re-examines Greene's data, adding observations for 1990 and focusing on model-selection issues in time-series analysis. He finds that although Greene's autoregressive model is statistically valid, so are alternative specifications, notably those including lagged dependent variables. The latter produce long-run estimates of the rebound effect that substantially exceed the short-run estimates (roughly $31 \%$ vs. 11\%). ${ }^{4}$ Schimek (1996) uses data from a still longer time period and finds an even smaller short-run but a similarly large long-run rebound effect (29\%). ${ }^{5}$ Schimek accounts for federal CAFE regulations by including a time trend for years since 1978; he also includes dummy variables for the years 1974 and 1979, when gasoline-price controls were in effect, resulting in queues and sporadic rationing at service stations. These controls reduce the extent of autocorrelation in the residuals.

These aggregate studies highlight the possible importance of lagged dependent variables (inertia) for sorting out short-run and long-run effects. But they do not settle the issue because they have trouble disentangling the presence of a lagged dependent variable from the presence of autocorrelation. Their estimates of these dynamic properties are especially sensitive to the time period considered and to their treatment of the CAFE regulations.

\footnotetext{
${ }^{3}$ Another study that found autocorrelation is that by Blair, Kaserman, and Tepel (1984). They obtain a rebound effect of $30 \%$, based on monthly data from Florida from 1967 through 1976. They do not estimate models with lagged variables.

${ }^{4}$ These figures are from the linear lagged dependent variable model (model III in Table 1). Estimates for the loglinear model are nearly identical.

${ }^{5}$ These figures are his preferred results, from Schimek (1996), p. 87, Table 3, model (3).
} 
Another type of study relies on pooled cross-sectional time-series data at a smaller geographical level of aggregation. Haughton and Sarkar (1996) construct such a data set for the 50 U.S. States and the District of Columbia, from 1970 to 1991 . Fuel prices vary by state, primarily but not exclusively because of different rates of fuel tax, providing an additional opportunity to observe the effects of fuel price on travel. The authors estimate equations both for VMT per driver and for fuel intensity (the inverse of fuel efficiency), obtaining a rebound effect of about $16 \%$ in the short run and $22 \%$ in the long run. ${ }^{6}$ Here, autocorrelation and the effects of a lagged dependent variable are measured with sufficient precision to distinguish them; they obtain a statistically significant coefficient on the lagged dependent variable, implying a substantial difference between long and short run. Tackling yet another dynamic issue, Haughton and Sarkar find that fuel efficiency is unaffected by the current price of gasoline unless that price exceeds its historical peak - a kind of hysteresis. In that equation, CAFE is taken into account through a variable measuring the difference between the legal minimum in a given year and the actual fuel efficiency in 1975. However, that variable is so strongly correlated with the historical maximum real price of gasoline that they omit it in most specifications, casting doubt on whether the resulting estimates, especially of hysteresis, really control adequately for the CAFE regulation.

It appears that the confounding of dynamics with effects of the CAFE regulation is a limiting factor in many studies. There is no agreement on how to control for CAFE, and results seem sensitive to the choice. This is partly because the standards were imposed at about the same time that a major increase in fuel prices occurred. But it is also because the control variables used are not constructed from an explicit theory of how CAFE worked. We attempt to remedy this in our empirical work.

Studies measuring the rebound effect using micro data show a wider disparity of results than those based on aggregate data, covering a range from zero to about $90 \%$. Two recent such studies use a cross section for a single year. West (2004), using the 1997 Consumer Expenditure Survey, estimates a rebound effect that diminishes strongly with income (across consumers) but is $87 \%$ on average, much higher than most studies. By contrast, Pickrell and Schimek (1999), using 1995 cross-sectional data from the National Personal Transportation Survey (NTPS),

\footnotetext{
${ }^{6}$ This paragraph is based on models $\mathrm{E}$ and $\mathrm{F}$ in their Table 1, p. 115. Their variable, "real price of gasoline per mile," is evidently the same as fuel cost per mile.
} 
obtain a rebound effect of just $4 \%{ }^{7}$ There are a number of reasons to be cautious about these results. West obtains an extremely low income-elasticity for travel, namely 0.02 , in the theoretically preferred model which accounts for endogeneity between vehicle-type choice and vehicle use. Pickrell and Schimek's results are sensitive to whether or not they include residential density as an explanatory variable, apparently because residential density is collinear with fuel price. We think the value of cross-sectional micro data for a single year is limited by the fact that measured fuel prices vary only across states, and those variations are correlated with unobserved factors that also influence VMT - factors such as residential density, congestion, and market penetration of imports. In our work, we eliminate the spurious effects of such crosssectional correlations by using fixed-effects specification, i.e. by including a dummy variable for each state.

Two recent studies use micro data covering several different years, thereby taking advantage of additional variation in fuel price and other variables. Goldberg (1998) estimates the rebound effect using the Consumer Expenditure Survey for the years 1984-1990, as part of a larger equation system that also predicts automobile sales and prices. When estimated by Ordinary Least Squares (OLS), her usage equation implies a rebound effect (both short- and long-run, because the equation lacks a lagged variable) of about $20 \%{ }^{8}$ Greene, Kahn, and Gibson (1999) use micro data from the Residential Transportation Energy Consumption Survey and its predecessor, for six different years between 1979 and 1994. Their usage equation is part of a simultaneous system including vehicle type choice and actual fuel price paid by the individual. They estimate the rebound effect at $23 \%$ for all households (short- and long-run assumed identical), with a range from $17 \%$ for three-vehicle households to $28 \%$ for one-vehicle households.

Several micro studies estimate model systems in which vehicle choice and usage are chosen simultaneously, thereby accounting for the endogeneity of fuel efficiency. ${ }^{9}$ Mannering

\footnotetext{
${ }^{7}$ Their model 3, with odometer readings as dependent variable. They actually measure the elasticity of VMT with respect to gasoline price, $\varepsilon_{M, P F}$, which is equal to $\varepsilon_{M, P M}$ as defined here.

${ }^{8}$ When estimated using instrumental variables to account for the endogeneity of vehicle type, Goldberg's estimate diminishes to essentially zero. But in that model the variables representing vehicle type attain huge yet statistically insignificant coefficients (see her Table I), casting doubt in our minds on the ability of the data set to adequately account for simultaneity.

${ }^{9}$ Examples include Train (1986), Hensher et al. (1992), Goldberg (1998), and West (2004).
} 
(1986) explicitly addresses the bias resulting from such endogeneity, finding it to be large, although in the direction opposite to what we expect: his estimate of $\left|\varepsilon_{M, P M}\right|$ becomes considerably greater when endogeneity is taken into account. ${ }^{10}$

Thus prior literature shows that aggregate estimates of the rebound effect, especially of the long-run effect, are sensitive to specification - in particular to the treatment of time patterns and CAFE standards. Disaggregate studies tend to produce a greater range of estimates; but those that exploit both cross-sectional and temporal variation are more consistent, finding a long-run rebound effect in the neighborhood of 20-25 percent. These results parallel those of three more comprehensive reviews, which report rebound estimates from numerous studies with means of 10-16 percent for short-run and 26-31 percent for long-run rebound effect. ${ }^{11}$ Overall, we would regard long-run estimates of anywhere between 20 and 30 percent as compatible with previous studies, but we see less consensus on short-run estimates.

\section{Theoretical Foundations and Empirical Specification}

\subsection{System of Simultaneous Equations}

Our empirical specification is based on a simple aggregate model that simultaneously determines VMT, vehicles, and fuel efficiency. We assume that consumers in each state choose how much to travel accounting for the size of their vehicle stock and the per-mile fuel cost of driving (among other things). They choose how many vehicles to own accounting for the price of new vehicles, the cost of driving, and other characteristics. Fuel efficiency is determined jointly by consumers and manufacturers accounting for the price of fuel, the regulatory environment, and their expected amount of driving; this process may include manufacturers' adjustments of the relative prices of various models, consumers' adjustments via purchases of various models (including light trucks), consumers' decisions about vehicle scrappage, and driving habits.

These assumptions lead to the following structural model:

\footnotetext{
${ }^{10}$ This could occur if people who drive a lot spend more time in stop-and-go traffic, or if they invest more heavily in fuel-consuming amenities like air conditioning or stronger acceleration.

${ }^{11}$ De Jong and Gunn (2001), Table 2; Graham and Glaister (2002), p. 23; Goodwin, Dargay, and Hanly (2004), Tables 3, 4. The National Research Council (2002, p. 19), without distinguishing short from long run, quotes 10-20 percent.
} 


$$
\begin{aligned}
& M=M\left(V, P_{M}, X_{M}\right) \\
& V=V\left(M, P_{V}, P_{M}, X_{V}\right) \\
& E=E\left(M, P_{F}, R_{E}, X_{E}\right)
\end{aligned}
$$

where $M$ is aggregate VMT per adult; $V$ is the size of the vehicle stock per adult; $E$ is fuel efficiency; $P_{V}$ is a price index for new vehicles; $P_{F}$ is the price of fuel; $P_{M} \equiv P_{F} / E$ is the fuel cost per mile; $X_{M}, X_{V}$ and $X_{E}$ are exogenous variables (including constants); and $R_{E}$ represents regulatory measures that directly or indirectly influence fleet-average fuel efficiency.

The standard definition of the rebound effect can be derived from a partially reduced form of (1), which is obtained by substituting the second equation into the first and solving for $M$. Denoting the solution by $\hat{M}$, this produces:

$$
\hat{M}=M\left[V\left(\hat{M}, P_{V}, P_{M} X_{V}\right), P_{M}, X_{M}\right] \equiv \hat{M}\left(P_{M}, P_{V}, X_{M}, X_{V}\right) .
$$

We call this equation a "partially reduced form" because $V$ but not $\mathrm{E}$ has been eliminated ( $E$ being part of the definition of $P_{M}$ ); thus we still must deal with the endogeneity of $P_{M}$ as a statistical issue. The rebound effect is just $-\varepsilon_{\hat{M}, P M}$, the negative of the elasticity of $\hat{M}(\cdot)$ with respect to $P_{M}$. By differentiating (2) and rearranging, we can write this elasticity in terms of the elasticities of structural system (1):

$$
\varepsilon_{\hat{M}, P M} \equiv \frac{P_{M}}{M} \cdot \frac{\partial \hat{M}}{\partial P_{M}}=\frac{\varepsilon_{M, P M}+\varepsilon_{M, V} \varepsilon_{V, P M}}{1-\varepsilon_{M, V} \varepsilon_{V, M}} .
$$

Strictly speaking, the estimation of a statistical model proves associations, not causation. However, one advantage of a structural model is that it makes explicit the pathways by which those associations occur and thus allows the analyst to make more informed judgments about whether causality is at work. It seems to us that the key relationships we are interested in, involving VMT, vehicle stock, fuel efficiency, income, and fuel price, are plausibly represented by interpreting each equation in (1) as causal. We therefore adopt this interpretation in describing our results.

\subsection{Empirical Implementation}

While most studies reviewed in the previous section are implicitly based on (2), we estimate the full structural model based on system (1). We generalize it in two ways to handle 
dynamics. First, we assume that the error terms in the empirical equations exhibit first-order serial correlation, meaning that unobserved factors influencing usage decisions in a given state will be similar from one year to the next: for example, laws governing driving by minors. Second, we allow for behavioral inertia by including the one-year lagged value of the dependent variable as a right-hand-side variable. Finally, we specify the equations as linear in parameters and with most variables in logarithms. Thus we estimate the following system:

$$
\begin{aligned}
& (\text { vma })_{t}=\alpha^{m} \cdot(\text { vma })_{t-1}+\alpha^{m v} \cdot(\text { vehstock })_{t}+\beta_{1}^{m} \cdot(\mathrm{pm})_{t}+\beta_{3}^{m} X_{t}^{m}+u_{t}^{m} \\
& (\text { vehstock })_{t}=\alpha^{v} \cdot(\text { vehstock })_{t-1}+\alpha^{v m} \cdot(v m a)_{t}+\beta_{1}^{v} \cdot(p v)_{t}+\beta_{2}^{v} \cdot(p m)_{t}+\beta_{3}^{v} X_{t}^{v}+u_{t}^{v} \\
& (\text { fint })_{t}=\alpha^{f} \cdot(\text { fint })_{t-1}+\alpha^{f m} \cdot(v m a)_{t}+\beta_{1}^{f} \cdot(p f)_{t}+\beta_{2}^{f} \cdot(\text { cafe })_{t}+\beta_{3}^{f} X_{t}^{f}+u_{t}^{f}
\end{aligned}
$$

with autoregressive errors:

$$
u_{t}^{k}=\rho^{k} u_{t-1}^{k}+\varepsilon_{t}^{k}, \quad k=m, v, f .
$$

Here, lower-case notation indicates that the variable is in logarithms. Thus $v m a$ is the natural logarithm of VMT per adult; vehstock is the log of number of vehicles per adult; and fint is the $\log$ of fuel intensity, defined as the reciprocal of fuel efficiency. Variable $p f$ is the log of fuel price; hence log fuel cost per mile, $p m$, is equal to $p f+f i n t$. Variable $p v$ is the log of a price index of new vehicles. The variable cafe measures fuel-efficiency regulation, as described below in Section 3.3.3. The individual variables in each vector $X_{t}^{k}$ may be in either levels or logarithms. Subscript $t$ designates a year, and $u$ and $\varepsilon$ are error terms assumed to have zero expected value, with $\varepsilon$ assumed to be "white noise".

Each lagged dependent variable can be interpreted as arising from a lagged adjustment process, in which the dependent variable moves slowly toward a new target value determined by current independent variables. The inertia of such movement can arise due to lack of knowledge, frictions in changing lifestyles, or slow turnover of the vehicle fleet state.

In system (4), equation (3) becomes:

$$
-b^{S}=\varepsilon_{\hat{M}, P M}=\frac{\varepsilon_{M, P M}+\alpha^{m v} \beta_{2}^{v}}{1-\alpha^{m v} \alpha^{v m}}
$$

where $b^{S}$ designates the short-run rebound effect. If variable $p m$ were included only in the form shown in (4), the structural elasticity $\varepsilon_{M, P M}$ would just be its coefficient in the usage equation, $\beta_{1}^{m}$. However, we include some variables in $X^{m}$ that are interactions of $p m$ with income, 
urbanization, and $\mathrm{pm}$ itself. Thus the elasticity, defined as the derivative of $v m a$ with respect to pm, varies with these measures. For convenience, we define the interaction variables in such a way that $\varepsilon_{M, P M}=\beta_{1}^{m}$ when computed at the mean values of variables in our sample. Since the other terms in (6) are small, this means that $-\beta_{1}^{m}$ is approximately the short-run rebound effect at those mean values.

To compute the long-run rebound effect, we must account for lagged values. The coefficient $\alpha^{m}$ on lagged $v m a$ in the usage equation indicates how much a change in one year will continue to cause changes in the next year, due perhaps to people's inability to make fast adjustments in lifestyle. If $\alpha^{m v}$ were zero, we could identify $\varepsilon_{M, P M}$ as the short-run rebound effect and $\varepsilon_{M, P M} /\left(1-\alpha^{m}\right)$ as the long-run rebound effect. More generally, the long-run rebound $b^{L}$ is defined by: ${ }^{12}$

$$
-b^{L}=\varepsilon_{\hat{M}, P M}^{L}=\frac{\varepsilon_{M, P M} \cdot\left(1-\alpha^{v}\right)+\alpha^{m v} \beta_{2}^{v}}{\left(1-\alpha^{m}\right)\left(1-\alpha^{v}\right)-\alpha^{m v} \alpha^{v m}} .
$$

The same considerations apply to other elasticities. It can be shown that the short- and long-run elasticities of vehicle usage with respect to new-car price are:

$$
\varepsilon_{\hat{M}, P V}^{S}=\frac{\alpha^{m v} \beta_{1}^{v}}{1-\alpha^{m v} \alpha^{v m}} ; \quad \varepsilon_{\hat{M}, P V}^{L}=\frac{\alpha^{m v} \beta_{1}^{v}}{\left(1-\alpha^{m}\right)\left(1-\alpha^{v}\right)-\alpha^{m v} \alpha^{v m}}
$$

and the short- and long-run elasticities of fuel intensity with respect to fuel price are approximately: ${ }^{13}$

$$
-\varepsilon_{\widetilde{E}, P F}^{S}=\frac{\beta_{1}^{f}+\alpha^{f m} \varepsilon_{M, P M}}{1-\alpha^{f m} \varepsilon_{M, P M}} ; \quad-\varepsilon_{\widetilde{E}, P F}^{L}=\frac{\beta_{1}^{f} \cdot\left(1-\alpha^{m}\right)+\alpha^{f m} \varepsilon_{M, P M}}{\left(1-\alpha^{f}\right)\left(1-\alpha^{m}\right)-\alpha^{f m} \varepsilon_{M, P M}} .
$$

Our data set is a cross-sectional time series, with each state observed 36 times. We use a fixed effects specification, which we find to be strongly favored over random-effects by a standard Hausman test. The commonly used two-step Cochrane-Orcutt procedure to estimate autocorrelation is known to be statistically biased when the model contains a lagged dependent

\footnotetext{
${ }^{12}$ Derivations of equations (7)-(9) can be found in Small and Van Dender (2005), section 5.1.

${ }^{13}$ The elasticities defined in (9) are those of $\widetilde{E}\left(P_{F}, P_{V}, R_{E}, X_{M}, X_{V}, X_{E}\right)$, the fully reduced-form equation for $E$ obtained by solving (1) for $M, V$, and $E$. The formulas given are approximations that ignore the effect of $p f$ on fint via the effect of vehicle stock on vehicle usage combined with the effect of vehicle usage on fuel intensity. This combined effect is especially small because it involves the triple product $\beta_{2}^{v} \alpha^{m v} \alpha^{f m}$, all of whose values are small.
} 
variable, as ours does (Davidson and MacKinnon, p. 336). Therefore we instead transform the model to a nonlinear one with no autocorrelation but with additional lags, and estimate it using nonlinear least squares. ${ }^{14}$

\subsection{Variables}

This section describes the main variables in (4) and their rationale. We identify each using both the generic notation in (1) and the variable name used in our empirical specification. Variables starting with lower case letters are logarithms of the variable described. All monetary variables are real. Data sources are given in Appendix A.

\subsubsection{Dependent Variables}

M: Vehicle miles traveled (VMT) divided by adult population, by state and year (logarithm: $v m a$, for "vehicle- $\underline{m i l e s}$ per adult").

$V$ : Vehicle stock divided by adult population (logarithm: vehstock).

$1 / E$ : Fuel intensity, $F / M$, where $F$ is highway use of gasoline (logarithm: fint).

\subsubsection{Independent Variables other than CAFE}

$P_{M}: \quad$ Fuel cost per mile, $P_{F} / E$. Its logarithm is denoted $p m \equiv \ln \left(P_{F}\right)-\ln (E) \equiv p f+f i n t$. For convenience in interpreting interaction variables based on $\mathrm{pm}$, we have normalized it by subtracting its mean over the sample.

$P_{V}: \quad$ Index of real new vehicle prices $(1987=100)(\operatorname{logarithm:} p v){ }^{15}$

$P_{F}$ : Price of gasoline, deflated by consumer price index $(1987=1.00)$ (cents per gallon). Variable $p f$ is its logarithm normalized by subtracting the sample mean.

$X_{M}, X_{V}, X_{E}$ : See Appendix A. $X_{M}$ includes $(p m)^{2}$ and interactions between normalized $p m$ and two other normalized variables: log real income (inc) and fraction urbanized (Urban). All

\footnotetext{
${ }^{14}$ If the original model is $y_{t}=x_{t}^{\prime} \beta+u_{t}$, with $u_{t}$ first-order serially correlated with parameter $\rho$, then the transformed model is $y_{t}=\rho y_{t-1}+\left(x_{t}-\rho x_{t-1}\right)^{\prime} \beta+\varepsilon_{t}$ with $\varepsilon_{t}$ serially uncorrelated. This transformation is the standard option for autocorrelated models in the computer package Eviews 5, which we use: see Quantitative Micro Software (2004), equation (17.10).

${ }^{15} \mathrm{We}$ include new-car prices in the second equation as indicators of the capital cost of owning a car. We exclude used-car prices because they are likely to be endogenous; also reliable data by state are unavailable.
} 
equations include time trends to proxy for unmeasured systemwide changes such as residential dispersion, other driving costs, lifestyle changes, and technology.

\subsubsection{Variable to Measure CAFE Regulation $\left(R_{E}\right)$}

We define a variable measuring the tightness of CAFE regulation, starting in 1978, based on the difference between the mandated efficiency of new passenger vehicles and the efficiency that would be chosen in the absence of regulation. The variable becomes zero when CAFE is not binding or when it is not in effect. In our system, this variable helps explain the efficiency of new passenger vehicles, while the lagged dependent variable in the fuel-intensity equation captures the inertia due to slow turnover of the vehicle fleet.

The calculation proceeds in four steps, described more fully in Appendix B. First, we estimate a reduced-form equation explaining log fuel intensity from 1966-1977. Next, this equation is interpreted as a partial adjustment model, so that the coefficient of lagged fuel intensity enables us to form a predicted desired fuel intensity for each state in each year, including years after 1977. Third, for a given year, we average desired fuel intensity (in levels, weighted by vehicle-miles traveled) across states to get a national desired average fuel intensity. Finally, we compare the reciprocal of this desired nationwide fuel intensity to the minimum efficiency mandated under CAFE in a given year (averaged between cars and light trucks using VMT weights, and corrected for the difference between factory tests and real-world driving). The variable cafe is defined as the difference between the logarithms of mandated and desired fuel efficiency, truncated below at zero.

The comparison is shown in Figure 1. We see that the desired efficiency of new vehicles (upper curve with long dashes) was mildly increasing over much of our time period, especially 1975-1979 and 1984-1997. There were one-year upticks in 1974 and 1979, presumably due to queues at gasoline stations, ${ }^{16}$ and some leveling in 1988-1991, 1998, and 2001 due to decreases in real fuel prices. The CAFE standard exhibited a very different pattern, rising rapidly from 1978-1984 and then flattening out. We can see that by this definition, the CAFE standard has been binding throughout its time of application, but that its tightness rose dramatically during its

\footnotetext{
${ }^{16}$ The uptick in 1979 is due to our assumption that the gasoline queues in 1979 would have the same effect on desired efficiency as those in 1974, which are captured by the 1974 dummy variable in the equation for fuel intensity fit on 1966-1977 data.
} 
first six years and then gradually diminished until it is just barely binding in 2001. This pattern, shown in the lower part of the figure (curve with long dashes) is obviously quite different from a trend starting at 1978 and from the CAFE standard itself, both of which have been used as a variable in VMT equations by other researchers.

Implicit in the definition of our regulatory variable is a view of the CAFE regulations as exerting a force on every state toward greater fuel efficiency of its fleet, regardless of the desired fuel efficiency in that particular state. Our reason for adopting this view is that the CAFE standard applies to the nationwide fleet average for each manufacturer; the manufacturer therefore has an incentive to use pricing or other means to improve fuel efficiency everywhere, not just where it is low.

Also shown in Figure 1 is an alternate calculation of desired fuel efficiency (curves with short dashes). This calculation, explained more fully in Appendix B, involves yet another step, which is to reestimate the reduced-form equation predicting desired log fuel intensity on the entire sample period, instead of just the pre-CAFE period. We do this by using the cafe variable just described (with one modification, which is that the trend is excluded from the estimating equation from which the variable is extracted) as a preliminary regulatory variable. The advantage of this alternate version is that the equation for desired efficiency is estimated with greater precision. However, it is also less robust with respect to inclusion or omission of trend variables, so we prefer our original ("base”) version for subsequent statistical analysis. As we shall see, they give nearly identical results for the rebound effect and most other elasticities. 


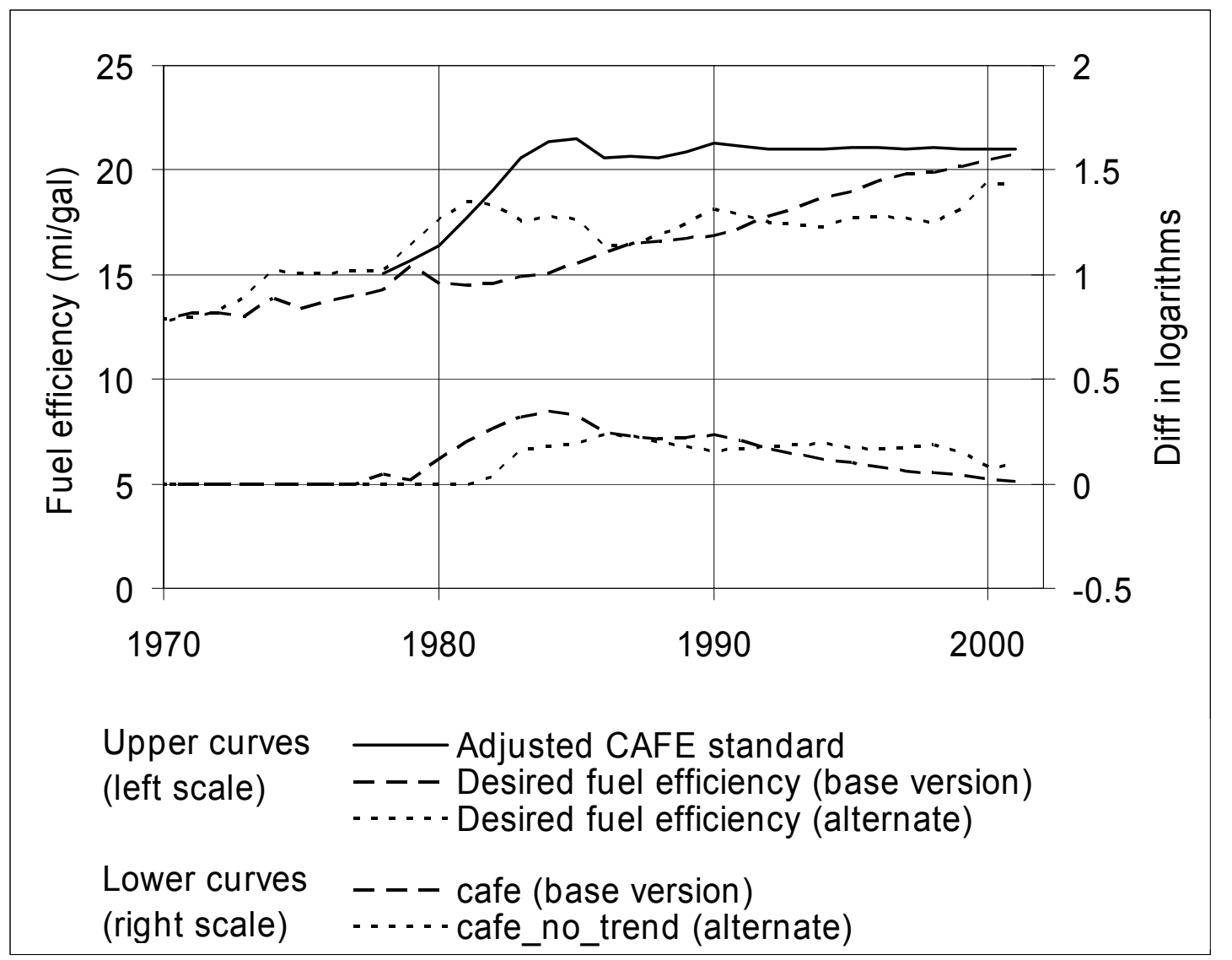

Figure 1. Desired and Mandated Fuel Efficiencies and Corresponding cafe Variables

\subsubsection{State population data}

Several variables of our specification, including the first two endogenous variables, make use of data on adult or total state population. Such data are published by the U.S. Census Bureau as midyear population estimates; they use demographic information at the state level to update the most recent census count, taken in years ending with zero. However, these estimates do not always match well with the subsequent census count, and the Census Bureau does not update them to create a consistent series. As a result, the published series contains many instances of implausible jumps in the years of the census count. For our preferred specification, we apply a 
correction assuming that the census counts are accurate and that the error in estimating population between them grows linearly over that ten-year time interval. ${ }^{17}$

We believe this approach is better than using the published estimates because it makes use of Census year data that were not available at the time the published estimates were constructed (namely, data from the subsequent census count). It should also be better than a simple linear interpolation between Census counts, because it incorporates relevant demographic information that is contained in the published population estimates. ${ }^{18}$ The impact of using either of these alternative population estimates is noticeable but not major. The published data yield the highest estimates of the long-run rebound effect (25.8\% in the long run), while the linear interpolation produces the lowest estimate (20.6\%); these values bracket the result of $22.2 \%$ using our preferred data.

The considerable difficulties we encountered in measuring adult population, by state and year, have discouraged us from seeking to refine our specification with additional variables measuring the age distribution of the adult population, even though they are known to have effects on vehicle ownership and travel.

\subsubsection{Data Summary}

Table 1 shows summary statistics for the data used in our main specification. We show them for the original rather than the logged version of variables; we also show the logged version after normalization for those variables that enter the specification through interactions.

\footnotetext{
${ }^{17}$ We estimate this 10-year cumulated error by extrapolating from the ninth year's figure: namely, it is $\left(\Delta P_{10}\right)=$ $\left[\mathrm{P}_{0}+(10 / 9) \cdot\left(P_{9}-P_{0}\right)\right]-P_{10}$, where $P_{y}$ is the published value in the $y$-th year following the most recent count. We then replace the published value $P_{y}$ by $P_{y}^{c}=P_{y}-(y / 10) \cdot \Delta P_{10}$.

${ }^{18}$ Our corrected value in year $y$ can be written as $P_{y}^{c}=P_{y}^{\mathrm{int}}+\left\{P_{y}-P_{y}^{\mathrm{int}-9}\right\}$, where $P_{y}^{\mathrm{int}}$ is the interpolated value between census counts and $P_{y}^{\text {int-9 }}$ is the interpolated value between years 0 and 9 . In other words, it adjusts $P_{y}^{\text {int }}$ by accounting for how the inter-census estimate $P_{y}$ differs from the nine-year linear trend of inter-census estimates.
} 
Table 1. Summary Statistics for Selected Variables

\begin{tabular}{llrrrr}
\hline Name & Definition & Mean & Std. Dev. & Min. & Max. \\
\hline Vma & VMT per adult & 10,929 & 2,538 & 4,748 & 23,333 \\
Vehstock & Vehicles per adult & 0.999 & 0.189 & 0.453 & 1.743 \\
Fint & Fuel intensity (gal/mi) & 0.0615 & 0.0124 & 0.0344 & 0.0919 \\
Pf & Fuel price, real (cents/gal) & 108.9 & 23.5 & 60.3 & 194.9 \\
pf & log Pf, normalized & 0 & 0.2032 & -0.5696 & 0.6033 \\
Pm & Fuel cost/mile, real (cents/mi) & 6.814 & 2.275 & 2.782 & 14.205 \\
pm & log Pm, normalized & 0 & 0.3490 & -0.8369 & 0.7935 \\
Income & Income per capita, real & 14,588 & 3,311 & 6,448 & 27,342 \\
inc & log Income, normalized & 0 & 0.2275 & -0.7909 & 0.6538 \\
Adults/road-mile & Adults per road mile & 57.73 & 68.27 & 2.58 & 490.20 \\
Pop/adult & Population per adult & 1.4173 & 0.0901 & 1.2265 & 1.7300 \\
Urban & Fraction of pop. in urban areas & 0.7129 & 0.1949 & 0.2895 & 1.0000 \\
Railpop & Fraction of pop. in metro areas & 0.0884 & 0.2073 & 0.0000 & 1.0000 \\
& served by heavy rail & & & & \\
Pv & Price of new vehicles (index) & 1.066 & 0.197 & 0.777 & 1.493 \\
Interest & Interest rate, new-car loans (\%) & 10.83 & 2.41 & 7.07 & 16.49 \\
Licenses/adult & Licensed drivers per adult & 0.905 & 0.083 & 0.625 & 1.149 \\
\hline
\end{tabular}

Notes: Units are as described in Appendix A.

Variables with capitalized names are shown as levels, even if it is their logarithm that enters our

specification. Variable Urban is shown unnormalized, although it is normalized when entering our

\section{Results}

\subsection{Structural Equations}

The results of estimating the structural system are presented in Tables 2-4, excluding the estimated fixed-effect coefficients. Each table shows two different estimation methods: threestage least squares (3SLS) and ordinary least squares (OLS). ${ }^{19}$ We also carried out estimations

\footnotetext{
${ }^{19}$ For both 3SLS and 2SLS, the list of instrumental variables includes one lagged value of each exogenous variable and two lagged values of each dependent variable, as necessitated by the existence of both first-order correlation and lagged dependent variables in our specification: see Fair (1984, pp. 212-213) or Davidson and MacKinnon (1993, section 10.10). In addition, the inclusion in our specification of $p m^{\wedge} 2 \equiv(p f+f i n t)^{2}$ requires including as instruments those combinations of variables that appear when fint is replaced by its regression equation and $(p f+f i n t)^{2}$ is expanded. As noted by Wooldridge (2002, section 9.5), it is not usually practical to include every such combination separately; he suggests as a compromise using combinations of the composite variable fint_inst, defined as the predicted value of fint based on the coefficients of an OLS estimate of the fint equation. We adopt this suggestion by including $p f^{2}, p f^{*} f i n t$ inst, and (fint_inst $)^{2}$ among the instruments. This procedure ignores the endogeneity of vma
} 
by two-stage least squares (2SLS) and generalized method of moments (GMM), as discussed in Section 4.4.

The VMT equation (Table 2) explains how much driving is done by the average adult, holding constant the size of the vehicle stock. The coefficients on fuel cost per mile $(\mathrm{pm})$ and its interaction with income are precisely measured and in the expected direction; we discuss their magnitudes in the next subsection. Many other coefficients are also measured with good precision and demonstrate strong and plausible effects. The income elasticity of vehicle travel (conditional on fleet size and efficiency), at the mean value of $\mathrm{pm}$, is 0.11 in the short run and $0.11 /(1-0.79)=0.53$ in the long run. Each adult tends to travel more if there is a larger road stock available (negative coefficient on adults/road-mile) and if the average adult is responsible for more total people (pop/adult). Our measure of urbanization (Urban) has a statistically significant negative effect on driving; but the effect is small, perhaps indicating that adults/road-mile better captures the effects of congestion. ${ }^{20}$ The availability of rail transit has no discernible effect, probably because it does not adequately measure the transit options available. The two years 1974 and 1979 exhibited a lower usage, by about $4.4 \%$, other things equal. ${ }^{21}$

The negative effect of adults/road-mile can equivalently be viewed as confirmation that increasing road capacity produces some degree of induced demand, a result found by many other researchers. However, because we have data only on road-miles, not lane-miles, our findings are not directly comparable to other studies of induced demand. ${ }^{22}$

The coefficient on the lagged dependent variable implies considerable inertia in behavior, with people adjusting their travel in a given year by just 21 percent of the ultimate shift if a given

among the variables explaining fint in this first-stage OLS, but we think any resulting error is small because vma is just one of seven statistically significant variables explaining fint.

${ }^{20}$ The long-run difference in $\log (\mathrm{VMT})$ between otherwise identical observations with the smallest and largest urbanization observed in our sample (see Table 1 ) is only $0.0548 \times 0.7105 /(1-0.7907)=0.19$; whereas the corresponding variation with adults/road-mile is $0.0203 \times[\ln (490.2)-\ln (2.58)] /(1-0.7907)=0.51$.

${ }^{21}$ We get nearly identical coefficients if we include separate dummy variables for 1974 and 1979 . We thus combine them for parsimony and to simplify the construction of the variable cafe (which requires extrapolating from pre1979 to post-1979 behavior).

${ }^{22}$ Our implied long-run elasticity of VMT with respect to road-miles is $0.020 / /(1-0.7907) \approx 0.1$, considerably smaller than the long-run elasticities with respect to lane-miles of 0.8 found by Goodwin (1996, p. 51) and Cervero and Hansen (2002, p. 484). Probably this is because road-miles is an inadequate measure of capacity. We have not controlled for endogeneity of road-miles, but most researchers have found that such controls have little effect on the elasticity. 
change is maintained permanently. The equation exhibits only mild autocorrelation, giving us some confidence that our specification accounts for most influences that move sluggishly over time.

OLS overestimates the rebound effect, possibly because it attributes the relationship between VMT and cost per mile as the latter causing the former, whereas the full system shows that some of it is due to reverse causality. In this particular model, OLS overestimates the absolute value of the structural coefficient of cost per mile by $88 \%$.

Table 2. Vehicle-Miles Traveled Equation

\begin{tabular}{|c|c|c|c|c|}
\hline \multirow[b]{2}{*}{ Variable } & \multicolumn{2}{|c|}{ Estimated Using 3SLS } & \multicolumn{2}{|c|}{ Estimated Using OLS } \\
\hline & Coefficient & Stndrd. Error & Coefficient & Stndrd. Error \\
\hline $\operatorname{vma}(\mathrm{t}-1)$ & 0.7907 & 0.0128 & 0.7421 & 0.0158 \\
\hline vehstock & $\mathbf{0 . 0 3 3 1}$ & 0.0110 & 0.0478 & 0.0126 \\
\hline $\mathrm{pm}$ & -0.0452 & 0.0048 & -0.0852 & 0.0051 \\
\hline $\mathrm{pm}^{\wedge} 2$ & -0.0104 & 0.0068 & 0.0152 & 0.0088 \\
\hline pm*inc & 0.0582 & 0.0145 & 0.0768 & 0.0194 \\
\hline pm*Urban & 0.0255 & 0.0106 & 0.0159 & 0.0144 \\
\hline inc & 0.1111 & 0.0141 & 0.1103 & 0.0157 \\
\hline adults/road-mile & -0.0203 & 0.0049 & -0.0178 & 0.0068 \\
\hline pop/adult & 0.1487 & 0.0461 & 0.0238 & 0.0513 \\
\hline Urban & -0.0548 & 0.0202 & -0.0514 & 0.0226 \\
\hline Railpop & -0.0056 & 0.0063 & -0.0002 & 0.0089 \\
\hline D7479 & -0.0442 & 0.0035 & -0.0367 & 0.0035 \\
\hline Trend & 0.0004 & 0.0004 & -0.0009 & 0.0004 \\
\hline constant & 1.9950 & 0.1239 & 2.5202 & 0.1522 \\
\hline rho & -0.0942 & 0.0233 & -0.0147 & 0.0295 \\
\hline No. observations & \multicolumn{2}{|c|}{1,734} & \multicolumn{2}{|c|}{1,734} \\
\hline Adjusted R-squared & \multicolumn{2}{|c|}{0.9801} & \multicolumn{2}{|c|}{0.9809} \\
\hline S.E. of regression & \multicolumn{2}{|c|}{0.0317} & \multicolumn{2}{|c|}{0.0311} \\
\hline Durbin-Watson stat & \multicolumn{2}{|c|}{1.9181} & \multicolumn{2}{|c|}{1.9927} \\
\hline Sum squared resid & \multicolumn{2}{|c|}{1.6788} & \multicolumn{2}{|c|}{1.6156} \\
\hline
\end{tabular}

Notes: Bold or italic type indicates the coefficient is statistically significant at the $5 \%$ or $10 \%$ level, respectively. Estimates of fixed effects coefficients (one for each state except Wyoming) not shown.

OLS here means single-equation least squares accounting for autocorrelation but with no instrumental variables. It is estimated non-linearly (see note 14.)

Variables inc, Urban, and the components of $\mathrm{pm}$ are normalized by subtracting their sample mean values, prior to forming interaction variables. Thus, the coefficient of any non-interacted variable gives the effect of that variable on vma at the mean values of other variables. 
In the vehicle stock equation (Table 3 ), the cost of driving a mile has no significant effect. New-car price and income do have significant effects, as do road provision (adults/roadmile), the proportion of adults having drivers' licenses (licences/adult), and credit conditions (interest). As expected, there is strong inertia in expanding or contracting the vehicle stock, as indicated by the coefficient 0.845 on the lagged dependent variable. This means that any shortrun effect on vehicle ownership, for example from an increase in income, will be magnified by a factor of $1 /(1-0.845)=6.45$ in the long run. This presumably reflects the transaction costs of buying and selling vehicles as well as the time needed to adjust planned travel behavior.

\section{Table 3. Vehicle Stock Equation}

\begin{tabular}{|c|c|c|c|c|}
\hline \multirow[b]{2}{*}{ Variable } & \multicolumn{2}{|c|}{ Estimated Using 3SLS } & \multicolumn{2}{|c|}{ Estimated Using OLS } \\
\hline & Coefficient & Stndrd. Error & Coefficient & Stndrd. Error \\
\hline $\operatorname{vehstock}(\mathrm{t}-1)$ & 0.8450 & 0.0148 & $\mathbf{0 . 8 3 9 7}$ & 0.0152 \\
\hline vma & 0.0238 & 0.0161 & 0.0434 & 0.0148 \\
\hline pv & -0.0838 & 0.0383 & -0.0792 & 0.0391 \\
\hline $\mathrm{pm}$ & -0.0009 & 0.0065 & 0.0065 & 0.0065 \\
\hline inc & 0.0391 & 0.0155 & $\mathbf{0 . 0 3 3 0}$ & 0.0156 \\
\hline adults/road-mile & -0.0228 & 0.0070 & -0.0214 & 0.0072 \\
\hline interest & -0.0143 & 0.0071 & -0.0176 & 0.0073 \\
\hline licenses/adult & 0.0476 & 0.0191 & 0.0525 & 0.0197 \\
\hline Trend & -0.0015 & 0.0008 & -0.0014 & 0.0008 \\
\hline constant & -0.0618 & 0.1581 & -0.2480 & 0.1463 \\
\hline rho & -0.1319 & 0.0281 & -0.1238 & 0.0290 \\
\hline No. observations & \multicolumn{2}{|c|}{1,734} & \multicolumn{2}{|c|}{1,734} \\
\hline Adjusted R-squared & \multicolumn{2}{|c|}{0.9645} & \multicolumn{2}{|c|}{0.9645} \\
\hline S.E. of regression & \multicolumn{2}{|c|}{0.0360} & \multicolumn{2}{|c|}{0.0360} \\
\hline Durbin-Watson stat & \multicolumn{2}{|c|}{1.9487} & \multicolumn{2}{|c|}{1.9548} \\
\hline Sum squared resid & \multicolumn{2}{|c|}{2.1668} & \multicolumn{2}{|c|}{2.1639} \\
\hline
\end{tabular}

Notes: Bold or italic type indicates the coefficient is statistically significant at the $5 \%$ or $10 \%$ level, respectively. Estimates of fixed effects coefficients (one for each state except Wyoming) not shown.

OLS here means single-equation least squares accounting for autocorrelation but with no instrumental variables. It is estimated non-linearly (see note 14.)

The results for fuel intensity (Table 4) show a substantial effect of annual fuel cost, in the expected direction. The effect of fuel price remains strong even if we allow the two components 
of annual fuel cost, namely $p f$ and $v m a$, to have separate coefficients. ${ }^{23}$ This is consistent with prior strong evidence that people respond to fuel prices by altering the efficiency of new-car purchases. The results also suggest that CAFE regulation had a substantial effect of enhancing the fuel efficiency of vehicles - at its maximum value of 0.35 in 1984, the cafe variable increased long-run desired fuel efficiency by 21 percent. ${ }^{24}$ Urbanization appears to increase fuel efficiency, perhaps due to a preference for small cars in areas with tight street and parking space. The time trends show a gradual tendency toward more fuel-efficient cars, starting in 1974 and accelerating in 1980 - possibly reflecting the gradual development and dissemination of new automotive technology in response to the fuel crises in those years. Like vehicle stock, fuel intensity demonstrates considerable inertia, presumably reflecting the slow turnover of vehicles.

\footnotetext{
${ }^{23}$ In this specification we are unable to identify separately the effects of $p f$ and $v m a$ with anything like satisfactory precision. In simpler specifications (see Section 4.4), we are able to separate them and we then find that fuel price remains statistically significant.

${ }^{24}$ In 1984 , the cafe variable changes the logarithm of desired efficiency by $+0.1011 \times 0.35 /(1-0.8138)=0.190$, and $\exp (0.190)=1.21$. The alternative version of the cafe variable, depicted in Figure 1, reaches its maximum in 1986, and at this value increases long-run desired fuel efficiency by $\exp \{0.1368 \times 0.23 /(1-0.8075)\}$, or $18 \%$.
} 


\begin{tabular}{|c|c|c|c|c|}
\hline \multirow[b]{3}{*}{ Variable } & \multicolumn{4}{|c|}{ Table 4. Fuel Intensity Equation } \\
\hline & \multicolumn{2}{|c|}{ Estimated Using 3SLS } & \multicolumn{2}{|c|}{ Estimated Using OLS } \\
\hline & Coefficient & Stndrd. Error & Coefficient & Stndrd. Error \\
\hline fint $(t-1)$ & 0.8138 & 0.0137 & 0.7894 & 0.0162 \\
\hline $\mathrm{vma}+\mathrm{pf}$ & -0.0460 & 0.0069 & -0.0934 & 0.0075 \\
\hline cafe & -0.1011 & 0.0115 & -0.1018 & 0.0144 \\
\hline inc & 0.0025 & 0.0163 & 0.0082 & 0.0172 \\
\hline pop/adult & -0.0111 & 0.0691 & 0.0607 & 0.0814 \\
\hline Urban & -0.1500 & 0.0522 & -0.1528 & 0.0663 \\
\hline D7479 & -0.0105 & 0.0045 & -0.0056 & 0.0046 \\
\hline Trend66-73 & 0.0006 & 0.0010 & 0.0015 & 0.0013 \\
\hline Trend74-79 & -0.0024 & 0.0010 & 0.0006 & 0.0012 \\
\hline Trend80+ & -0.0037 & 0.0004 & -0.0047 & 0.0005 \\
\hline constant & -0.1137 & 0.0809 & $\mathbf{0 . 2 3 5 7}$ & 0.0903 \\
\hline rho & -0.1353 & 0.0236 & -0.0966 & 0.0292 \\
\hline No. observations & \multicolumn{2}{|c|}{1,734} & \multicolumn{2}{|c|}{1,734} \\
\hline Adjusted R-squared & \multicolumn{2}{|c|}{0.9604} & \multicolumn{2}{|c|}{0.9611} \\
\hline S.E. of regression & \multicolumn{2}{|c|}{0.0398} & \multicolumn{2}{|c|}{0.0394} \\
\hline Durbin-Watson stat & \multicolumn{2}{|c|}{1.9515} & \multicolumn{2}{|c|}{2.0571} \\
\hline Sum squared resid & \multicolumn{2}{|c|}{2.6424} & \multicolumn{2}{|c|}{2.5961} \\
\hline
\end{tabular}

Notes: Bold or italic type indicates the coefficient is statistically significant at the $5 \%$ or $10 \%$ level, respectively. Estimates of fixed effects coefficients (one for each state except Wyoming) not shown.

OLS here means single-equation least squares accounting for autocorrelation but with no instrumental variables. It is estimated non-linearly (see note 14.)

\subsection{Rebound Effects and Other Elasticities}

Table 5 shows the cost-per-mile elasticity of driving (the negative of the rebound effect) and some other elasticities implied by the structural models. The interactions through the simultaneous equations modify only slightly the numbers that can be read directly from the coefficients. In particular, the average cost-per-mile elasticity in the sample is -0.0452 , indistinguishable (within the precision shown) from the coefficient of $p m$ in Table 2. Thus the average rebound effect in this sample is estimated to be approximately $4.5 \%$ in the short run, and $22.2 \%$ in the long run. 


\section{Table 5. Rebound Effect and Other Price Elasticities}

\begin{tabular}{|c|c|c|c|c|}
\hline \multirow[b]{2}{*}{ Variable } & \multicolumn{2}{|c|}{ Estimated Using 3SLS } & \multicolumn{2}{|c|}{ Estimated Using OLS } \\
\hline & Short Run & Long Run & Short Run & Long Run \\
\hline \multicolumn{5}{|l|}{$\begin{array}{l}\text { Elasticity of VMT with respect to } \\
\text { fuel cost per mile: (a) }\end{array}$} \\
\hline At sample average & $\begin{array}{l}-0.0452 \\
(0.0048)\end{array}$ & $\begin{array}{l}-0.2221 \\
(0.0238)\end{array}$ & $\begin{array}{l}-0.0850 \\
(0.0052)\end{array}$ & $\begin{array}{l}-0.3398 \\
(0.0251)\end{array}$ \\
\hline At US 1997-2001 avg. (b) & $\begin{array}{l}-0.0216 \\
(0.0090)\end{array}$ & $\begin{array}{l}-0.1066 \\
(0.0433)\end{array}$ & $\begin{array}{l}-0.0806 \\
(0.0109)\end{array}$ & $\begin{array}{l}-0.3216 \\
(0.0438)\end{array}$ \\
\hline $\begin{array}{l}\text { At US } 1997-2001 \text { avg. if } \\
\text { pm stayed at '66-' } 01 \text { avg. (c) }\end{array}$ & $\begin{array}{l}-0.0311 \\
(0.0060) \\
\end{array}$ & $\begin{array}{l}-0.1531 \\
(0.0299)\end{array}$ & $\begin{array}{l}-0.0666 \\
(0.0068) \\
\end{array}$ & $\begin{array}{l}-0.2648 \\
(0.0311) \\
\end{array}$ \\
\hline $\begin{array}{l}\text { Elasticity of VMT with respect to } \\
\text { new veh price }\end{array}$ & $\begin{array}{l}-0.0028 \\
(0.0056) \\
\end{array}$ & $\begin{array}{l}-0.0876 \\
(0.0277) \\
\end{array}$ & $\begin{array}{l}-0.0038 \\
(0.0077) \\
\end{array}$ & $\begin{array}{l}-0.0964 \\
(0.0287) \\
\end{array}$ \\
\hline \multicolumn{5}{|l|}{$\begin{array}{l}\text { Elasticity of fuel intensity } \\
\text { with respect to fuel price: }\end{array}$} \\
\hline At sample average & $\begin{array}{l}-0.0440 \\
(0.0067) \\
\end{array}$ & $\begin{array}{l}-0.2047 \\
(0.0338) \\
\end{array}$ & $\begin{array}{l}-0.0861 \\
(0.0070) \\
\end{array}$ & $\begin{array}{l}-0.3480 \\
(0.0404) \\
\end{array}$ \\
\hline \multicolumn{5}{|l|}{$\begin{array}{l}\text { Elasticity of fuel consumption } \\
\text { with respect to fuel price: }\end{array}$} \\
\hline At sample average & $\begin{array}{l}-0.0873 \\
(0.0056)\end{array}$ & $\begin{array}{l}-0.3813 \\
(0.0277)\end{array}$ & $\begin{array}{l}-0.1638 \\
(0.0077)\end{array}$ & $\begin{array}{l}-0.5695 \\
(0.0287)\end{array}$ \\
\hline At US 1997-2001 avg. (b) & $\begin{array}{l}-0.0657 \\
(0.0095)\end{array}$ & $\begin{array}{l}-0.3097 \\
(0.0372)\end{array}$ & $\begin{array}{l}-0.1601 \\
(0.0132)\end{array}$ & $\begin{array}{c}-0.5616 \\
(0.0333)\end{array}$ \\
\hline $\begin{array}{l}\text { At US } 1997-2001 \text { avg. if } \\
\text { pm stayed at '66-' } 01 \text { avg. (c) }\end{array}$ & $\begin{array}{l}-0.0744 \\
(0.0065)\end{array}$ & $\begin{array}{l}-0.3380 \\
(0.0316)\end{array}$ & $\begin{array}{l}-0.1485 \\
(0.0087)\end{array}$ & $\begin{array}{l}-0.5377 \\
(0.0328)\end{array}$ \\
\hline
\end{tabular}

Notes: (a) The rebound effect is just the negative of this number (multiplied by 100 if expressed as a percent).

(b) Elasticities measured at the average 1997-2001 values of pm, inc, and Urban for all US.

(c) Same as (b) but setting the coefficient of $\mathrm{pm}^{\wedge} 2$ equal to zero.

Asymptotic standard errors in parentheses are calculated from the covariance matrix of estimated coefficients using the Wald test procedure for an arbitrary function of coefficients in Eviews 5.

Use of OLS overestimates the short- and long-run rebound effects by $88 \%$ and $53 \%$, respectively. The short-run OLS estimate $(8.5 \%)$ is well within the consensus of the literature, whereas our 3SLS estimate is somewhat below the consensus. This comparison might suggest that many estimates in the literature are overstated because of endogeneity bias. But such a conclusion would be speculative given the poor performance of the OLS specification on other grounds. We found the OLS results sensitive to slight changes in specification - sometimes indicating implausibly high autocorrelation and implausibly small coefficients on lagged 
dependent variables - whereas 2SLS and 3SLS results are quite robust. Thus differences among OLS results in the literature, and differences between those results and ours, may be caused as much by differences in specification as by endogeneity bias.

The model for vehicle usage discerns additional influences on the rebound effect. The coefficient on $\mathrm{pm}^{*}$ inc in Table 2 shows that a 0.1 increase in inc (i.e. a 10.5 percent increase in real income) reduces the magnitude of the short-run rebound effect by about 0.58 percentage points. This appears to confirm the theoretical expectation that higher incomes make people less sensitive to fuel costs. Urbanization has a smaller effect: a 10 percentage-point increase in urbanization reduces the rebound effect by about 0.25 percentage points. Finally, fuel cost itself raises the rebound effect as expected (coefficient of $p m^{\wedge} 2$ in Table 2), but only modestly and without statistical significance.

To get an idea of the implications of such variations, we compute the short- and long-run rebound effects for values of income, urbanization, and fuel costs of driving equal to those of the average state over the most recent five-year period covered in our data set, namely 1997-2001. Using the 3SLS results, we see that the short-run rebound effect is reduced to $2.2 \%$ and the longrun effect to $10.7 \%$ (second row in Table 5). If fuel prices in 1997-2001 had been 58 percent higher, corresponding roughly to the $\$ 2.35$ nominal price observed in the first two months of 2006, these figures would be $3.1 \%$ and $15.3 \%$, around two-thirds the values at the sample average. $^{25}$

Thus the rebound effect decreased in magnitude over our sample period; our base specification attributes this decrease mostly to rising incomes but partly to falling fuel prices. As we shall see in the next subsection, we could alternatively explain virtually all of the decline as due to rising incomes, by excluding $p m^{\wedge} 2$ from the specification. But these two alternate explanations have quite different implications for future scenarios. Most analysts would expect incomes to continue rising, but would expect fuel prices to rise rather than continue falling. Thus our use of a model including variable retaining $\mathrm{pm}^{\wedge} 2$ provides more conservative results for making projections into the future and also avoid inadvertently biasing results by omitting a theoretically justified variable solely because of our inability to estimate its coefficient with high precision.

\footnotetext{
${ }^{25}$ This scenario happens to put $p m$ at its sample average, and thus enables us also to see the effect of rising income without falling fuel prices.
} 
The second panel of Table 5 shows that higher new car prices reduce travel, but only by a small amount, with a long-run elasticity of -0.09 . The third and fourth panels provide information about how fuel prices affect fuel intensity and overall fuel consumption. The fuelprice elasticity of fuel intensity, given by equation (9), is estimated with good precision thanks to the small standard error on the coefficient of $v m a+p f$ in Table 4. Combining it with the elasticity of vehicle-miles traveled gives the total price-elasticity of fuel consumption, shown in the last panel of the table. ${ }^{26}$ The long-run estimate is -0.38 , within the range of recent studies reviewed by Parry and Small (2005) although somewhat lower than most. ${ }^{27}$

Thus, our results suggest that the response to fuel prices has become increasingly dominated by changes in fuel efficiency rather than changes in travel. Whether this remains the case after 2001 depends on how incomes and fuel costs of driving evolve. For example, our point estimates imply that the decline in rebound effect arising from growth in real income of one percent would be offset by an increase in real fuel cost per mile of about 2.8 percent. This in turn could be brought about by a 3.5 percent increase in real fuel price and the accompanying 0.7

\footnotetext{
${ }^{26}$ Writing the identity $F=M / E$, giving fuel consumption as a ratio of VMT and fuel efficiency, in its logarithmic form $f=m-e$, then differentiating with respect to $p_{F}$, the logarithm of fuel price, yields the following equation when we remember that $m$ depends on the logarithm of cost per mile, $p_{m}=p_{F}-e$ :

$$
\frac{d f}{d p_{F}}=\left(\frac{\partial m}{\partial p_{F}}-\frac{\partial m}{\partial i} \cdot \frac{d e}{d p_{F}}\right)-\frac{d e}{d p_{F}} .
$$

In elasticity terms, using notation similar to that in (7)-(9):

$$
\varepsilon_{F, P F}=\varepsilon_{\hat{M}, P M} \cdot\left(1-\varepsilon_{\widetilde{E}, P F}\right)-\varepsilon_{\widetilde{E}, P F}
$$

where $\varepsilon_{\hat{M}, P M}$ and $-\varepsilon_{\widetilde{E}, P F}$ are the elasticities reported in the first two panels of Table 5 . This equation is derived by USDOE (1996, p. 5-11) and Small and Van Dender (2005, eqn. 6). We regret that in the July 2006 version of this working paper, and in the subsequent published shorter version in Energy Journal (vol. 28, no. 1, 2007, pp. 25-51), we accidentally omitted the term in parentheses in equation (10) when computing $\varepsilon_{F, P F}$ for Table 5 and therefore overstated the magnitudes of $\varepsilon_{F, P F}$. Comparing the published 3SLS point estimates (last three rows of Table 5) with those shown here, we find they were overstated by $0.0010-0.0019$ for the short run and by $0.0243-0.0425$ for the long run, which is $2 \%$ of the correct value for the short run and $8-12 \%$ for the long run. The same correction applies to Table B2.

${ }^{27}$ Parry and Small (2005) choose the long-run price elasticity of fuel consumption equal to be -0.55 as the best consensus from the literature, with $40 \%$ of the elasticity due to mileage changes. By comparison, our estimate is -0.38 , with $46 \%$ of it due to changes in vehicle travel, computed from Table 5 as $0.2221 \cdot(1-0.2047) / 0.3815$. This proportion falls to $27 \%$ when computed for conditions prevailing in the last five years of our sample.
} 
percent fall in fuel intensity. ${ }^{28}$ To put it another way, a doubling of real fuel price would be offset by a 22 percent increase in real income in their influence on the rebound effect. ${ }^{29}$

\subsection{Estimates on separate time periods}

As noted, we find the rebound effect to be much smaller when computed for values of per capita income characterizing recent years than when computed for average values over the 36year estimation period. Would we see this same decline if we just estimated a model with a constant rebound effect on different time periods? We answered this question using three twelveyear time periods. The resulting estimates are considerably less precise and less robust, especially for the fuel intensity equation: its estimated autocorrelation coefficient is uncomfortably large in magnitude during the second and third time periods $(+0.47$ and -0.25$)$, and the estimates of the effect of cafe (for the two periods where it was in effect) show implausible variations. Furthermore, the coefficient of lagged vma in the usage equation is considerably smaller ( 0.55 to 0.58$)$ when estimated on these subsamples than when estimated on the full sample. Both problems may reflect the inability with such short time periods to clearly identify the nature of variation over time, especially given that two of the eleven years' data are lost because of using variables with two lags as instruments.

Nevertheless, the summary results in Table 6 clearly show the hypothesized decline in the rebound effect as we move from the first two periods to the last period. The table shows our 3SLS estimates of the short- and long-run rebound effect in each time period, and compares them with those predicted by our base model at the average values of variables for that period. Except for the first period, the long-run estimates agree closely with these full-model predictions. Shortrun estimates are mostly larger than the prediction. The first column of the table also shows that the average rebound effect estimated over the entire period does not depend strongly on whether

\footnotetext{
${ }^{28}$ These statements are approximate because they equate changes in logs to percentage changes and also because they ignore the small terms in $\alpha^{n v}$ in (6) and (7); they are also qualified by the fact that the effect of fuel prices is not statistically significant. The first statement is based on coefficients $\beta_{p m^{\wedge} 2}$ of $p m^{\wedge} 2$ and $\beta_{p m *} *_{i n c}$ of $p m \cdot$ inc in Table 2, remembering that $\partial \varepsilon_{M, P M} / \partial p m \equiv \partial^{2} v m a / \partial p m^{2}=2 \beta_{p m^{\wedge} 2}$ and $\partial \varepsilon_{M, P M} / \partial i n c \equiv \partial^{2} v m a / \partial p m \partial i n c=\beta_{p m^{*} i n c}$. The second statement is based on the long-run elasticity of fuel intensity with respect to fuel price in Table 5, which is constant over time in our specification except for the small terms in $\alpha^{\text {fm }}$ in (9); it implies that a fuel-price increase of 3.5 percent causes a change in fuel intensity of $-0.20 \times 3.5=0.7$ percent.

${ }^{29}$ The offsetting income change is computed from $\ln \left(\operatorname{Inc} c^{1} / \operatorname{Inc} c^{0}\right)=\Delta i n c=\Delta p_{F} / 3.5=(\ln 2) / 3.5=0.20$, so that $\operatorname{Inc}^{1} / \operatorname{Inc}^{0}$ $=\exp (0.20)=1.22$.
} 
the model includes interaction terms. The same is true if the rebound effect is allowed to vary with a simple time trend but not income or urbanization, although in that model the interaction term is not significant (results not shown).

Table 6. Rebound Effect Estimates from Different Time Periods

\begin{tabular}{lcccc} 
& Full Sample & \multicolumn{3}{c}{ Separate Subsamples } \\
\hline & $1966-2001$ & $1966-1977$ & $1978-1989$ & $1990-2001$ \\
\hline & & & & \\
Short run: & & & & \\
Estimated constant value & -0.0511 & -0.0724 & -0.0819 & -0.0366 \\
& $(0.0046)$ & $(0.0208)$ & $(0.0109)$ & $(0.0109)$ \\
Predicted from full model & -0.0452 & -0.0638 & -0.0465 & -0.0197 \\
& $(0.0048)$ & $(0.0055)$ & $(0.0044)$ & $(0.0083)$ \\
Long run: & & & & \\
Estimated constant value & -0.2620 & -0.1800 & -0.1963 & -0.0831 \\
& $(0.0249)$ & $(0.0475)$ & $(0.0297)$ & $(0.0255)$ \\
Predicted from full model & -0.2221 & -0.3235 & -0.2359 & -0.1006 \\
& $(0.0238)$ & $(0.0318)$ & $(0.0254)$ & $(0.0420)$ \\
\hline
\end{tabular}

Notes: Estimated standard errors are in parentheses. Results shown as "estimated constant value" are from a model estimated without $\mathrm{pm}^{\wedge} 2, \mathrm{pm} * \mathrm{inc}$, or $\mathrm{pm} *$ Urban . Results shown as "predicted from full model" are calculated from our base model in Tables 2-4 using the average values of $p m$, inc and Urban for the time period shown.

Thus this exercise lends support to our interpretation that the rebound effect has indeed declined between the time periods 1966-1989 and 1990-2001. Although we cannot say definitively that the reason is higher incomes, that explanation seems the most likely given its theoretical justification and good data fit.

\subsection{Other Specifications and Estimation Methods}

As we have seen, fuel prices are potentially important for the rebound effect; but their influence depends on a coefficient (that of $p m^{\wedge} 2$ ) whose estimate is statistically imprecise. We therefore explore here the behavior of the model if that term is omitted. We also show some 2SLS results for both the full model and this reduced model, in order to examine more carefully whether specification error in the model could be adversely affecting the 3SLS estimates. 
Comparisons are shown in Table 7, whose top panel repeats 3SLS results already presented in Tables 2 and 5 .

\begin{tabular}{|c|c|c|c|c|c|c|}
\hline \multicolumn{7}{|c|}{ Table 7. Models With and Without Squared Term in Fuel Cost per Mile } \\
\hline \multirow[b]{2}{*}{ Variable } & \multicolumn{2}{|c|}{ 3SLS } & \multicolumn{2}{|c|}{ 2SLS } & \multicolumn{2}{|c|}{ GMM } \\
\hline & Coeff. & Std. Err. & Coeff. & Std. Err. & Coeff. & Std. Err. \\
\hline \multicolumn{7}{|c|}{ Full Specification } \\
\hline pm & -0.0452 & 0.0048 & -0.0500 & 0.0052 & -0.0485 & 0.0036 \\
\hline $\mathrm{pm}^{\wedge} 2$ & -0.0104 & 0.0068 & 0.0077 & 0.0092 & 0.0055 & 0.0060 \\
\hline pm*(inc) & 0.0582 & 0.0145 & 0.1073 & 0.0198 & 0.0950 & 0.0134 \\
\hline pm*(Urban) & 0.0255 & 0.0106 & 0.0219 & 0.0145 & 0.0177 & 0.0096 \\
\hline \multicolumn{7}{|l|}{ LR Rebound Effect: } \\
\hline At sample average & -0.2221 & 0.0238 & -0.2293 & 0.0243 & -0.2378 & 0.0182 \\
\hline At $1997-2001$ avg. & -0.1066 & 0.0433 & -0.1437 & 0.0504 & -0.1517 & 0.0303 \\
\hline $\begin{array}{l}\text { At } 1997-2001 \text { avg. } \\
\text { but } p f=\$ 1.93\end{array}$ & -0.1531 & 0.0299 & -0.1114 & 0.0324 & -0.1271 & 0.0229 \\
\hline \multicolumn{7}{|c|}{ Simplified Specification Excluding $p^{\wedge}{ }^{\wedge} 2$} \\
\hline $\mathrm{pm}$ & -0.0464 & 0.0046 & -0.0466 & 0.0049 & -0.0449 & 0.0038 \\
\hline $\mathrm{pm}^{\wedge} 2$ & --- & --- & --- & --- & --- & --- \\
\hline pm*(inc) & 0.0881 & 0.0170 & 0.1038 & 0.0228 & 0.0944 & 0.0164 \\
\hline pm*(Urban) & 0.0126 & 0.0118 & 0.0200 & 0.0160 & 0.0212 & 0.0125 \\
\hline \multicolumn{7}{|l|}{ LR Rebound Effect: } \\
\hline At sample average & -0.2207 & 0.0234 & -0.2190 & 0.0246 & -0.2268 & 0.0208 \\
\hline At $1997-2001$ avg. & -0.1212 & 0.0314 & -0.1023 & 0.0366 & -0.1136 & 0.0275 \\
\hline
\end{tabular}

Note: Bold or italic type indicates the coefficient is statistically significant at the $5 \%$ or $10 \%$ level, respectively.

Several observations are prompted by comparing the four models defined by these two specifications and two estimation methods. First, all four models predict about the same average rebound effect over the sample: 4.5-5.0 percent in the short run, 22-23 percent in the long run. Second, the simplified specification exhibits less difference between 3SLS and 2SLS than the full specification. In particular, both 3SLS and 2SLS predict that the rebound effect is only about half as large in the latest five years as it is over the entire sample. Third, with 3SLS, the simplified specification is somewhat more conservative than the full specification in predicting how much the rebound effect has declined during the period; but it is more radical in the 
predicted effect of income because this simplified specification does not use fuel prices to help explain the decline.

Thus, the simplified specification behaves quite reliably and the full specification is similar to it except that it allows for an influence of fuel cost on the rebound effect. This leads us to prefer the full specification as the better source of point estimates and policy-relevant predictions, even though those predictions - if they involve changes in fuel cost per mile - are based on a statistically insignificant coefficient. Furthermore, the stability of the simplified specification lends support to the view that the model is well specified, making 3SLS a suitable estimator. Indeed, the table suggests that 2SLS has difficulty disentangling the effects of $p m$ and $p m^{\wedge} 2$ in the full specification - it yields a positive coefficient for $p m^{\wedge} 2$, opposite to the theoretical prediction. Statistically, this contrast is within sampling error but it does make 2SLS less satisfactory as a source of point estimates for policy analysis.

The third pair of columns in Table 7 shows the results of using a Generalized Method of Moments (GMM) estimator that allows the residuals to be correlated arbitrarily over time and for their variances to vary over time. Similarly, we estimated a GMM model (not shown) allowing for arbitrary contemporaneous correlation and heteroskedasticity across states. ${ }^{30} \mathrm{We}$ were prompted to try these estimators because Bertrand et al. (2004) suggests that 3SLS might understate standard errors due to heteroscedasticity or inadequate controls for time-varying unobserved effects. ${ }^{31}$ But in fact we see that the standard errors are little different with GMM. Most point estimates are the same also, but the GMM coefficient of $p m^{\wedge} 2$ switches to a theoretically implausible sign, although it remains statistically insignificant. We therefore prefer the 3SLS results on practical grounds, and are reassured that GMM produces essentially the same standard errors.

We also re-estimated our structural models using the alternative version of the cafe variable describing tightness of fuel efficiency regulations, described earlier. Results are shown in Appendix B. There is little difference except in the fuel intensity equation, where the effects of

\footnotetext{
${ }^{30}$ These estimates were implemented in EViews 5 using the GMM estimator with "White period" weights and "White cross section" weights, respectively. They are asymptotically efficient in different ways: the first as the number of time periods grows, the second as the number of cross-sectional observations grows. Either can be less efficient than 3SLS in finite samples, however (Wooldridge 2002, p. 196).

${ }^{31}$ In principle one could handle this concern by computing robust standard errors from the 3SLS results, but doing so is impractical due to the complexity of our model system. Such standard errors are calculated automatically by the GMM procedure.
} 
fuel price and cafe are both larger using the alternative version of cafe. This results in total fuel consumption responding more sensitively to changes in fuel prices or in the stringency of cafe standards.

To summarize, all models find that the rebound effect declined over the period. We prefer our base specification because it allows for a plausible set of reasons for this decline, and we prefer the 3SLS estimator because it provides theoretically correct signs for the relevant coefficients. In terms of policy, the full specification with 3SLS also happens to be the most conservative approach in explaining our main result, which is that the rebound effect declines with income. Assuming real income continues to grow, any of our models will project a further decline from this source in the future; but the magnitude of that predicted decline will be smaller using our preferred results than using any other models shown in Table 7 because our preferred results contain the smallest estimate of the coefficient of $p m^{*} i n c$.

\subsection{Caveats}

Despite the generally good performance of our equation system, we call attention to three limitations. First, there are well-known problems with the VMT data collected by the US Federal Highway Administration. These data are reported by states, which lack a uniform methodology for estimating them - for example, some rely on sporadic vehicle counts, while others multiply fuel consumption (measured from tax records) by an independent estimate of fleet fuel efficiency. $^{32}$

However, we have no reason to think that these problems bias our results. The posited sources of measurement error are mostly unrelated to our independent variables; and even if they were, our use of fixed effects eliminates the spurious effect of any cross-state relationship that is consistent over time. One might worry that errors in measuring fuel consumption by state could appear in both VMT data (in those states where the VMT estimate is based on fuel consumption) and in fuel efficiency. This would bias OLS estimates, but not 2SLS and 3SLS, which are

\footnotetext{
${ }^{32}$ VMT estimates in other data sets have problems as well. For example, the 1990 Nationwide Personal Transportation Survey (NPTS) changed its sampling method in a manner that exaggerated the measured 1983-1990 growth in VMT. Lave (1996) compares three sources in terms of national VMT growth rates, finding that the FHWA data set that we use (at the national level) agrees well with the other sources. For more recent years, it is generally believed that the FHWA methodology has improved.
} 
specifically designed to eliminate asymptotic bias resulting from correlated errors in the dependent variables. ${ }^{33}$

Second, our estimates, like those of most previous studies, rely on the theoretical restriction that people react to changes in cost per mile in the same way whether those changes arise from variations in fuel prices or in fuel efficiency. This restriction is critical to most studies because most data sets contain more variation in fuel prices than in fuel efficiency. Unfortunately, we are unable to confirm the restriction with our data and model.

Using the simplified specification of Table 7 as a starting point, we entered the two components of log fuel cost per mile, $p m=p f+f i n t$, separately each time $p m$ appears in our equations. Summary results are shown in Appendix C. A statistical test easily rejects equality of relevant coefficients. The coefficient on the non-interacted variable fint is small and statistically insignificant, while that on $p f$ retains about the same value as that on $p m$ in the restricted model. This result is consistent with the observation that variations in fuel prices are mainly what identify the rebound effect.

Thus in the absence of theory we cannot prove that there is any rebound effect defined as a reaction to exogenous changes in fuel efficiency. However, the model with $p f$ and fint entered separately does not perform very well. In the usage equation, the interactions of fint with inc and Urban become unstable with respect to inclusion or exclusion of other variables, making us think the equation is overfitting. With OLS, several coefficients of the usage equation, including that of fint, are implausible and erratic, and the equation portrays an extremely high value of autocorrelation and a low value for lagged vma. It appears that the time-series properties of the usage equation are poorly identified when $p f$ and fint are allowed to have separate effects. Thus we conclude that the best estimate of the rebound effect is obtained by imposing the theoretical constraint that equates the effects of fuel price and fuel intensity, and that our data are unable to test this constraint satisfactorily.

A third caveat is that the estimated role of fuel price in determining fuel efficiency is quite sensitive to details of how the cafe variable is defined. The prediction equation for desired fuel intensity, shown in Appendix B, is not very robust to attempts to add variables such as

\footnotetext{
${ }^{33}$ Furthermore, we measure fuel intensity as fuel consumption divided by VMT, causing a cancellation of a common error in both. Thus for states that estimate VMT from aggregate fuel consumption, measurement error in fuel consumption would appear in our VMT variable but not in our fuel intensity variable, which instead would be determined by the independent estimate of fleet fuel efficiency used in those states.
} 
lagged values of variables already included - probably because it relies on data for only a short time period, 1966-78. When we tried this, the time pattern exhibited by the cafe variable was quite different, and its influence in the structural model for fuel efficiency diminished to statistical insignificance, as did that of fuel price. However, we believe that this richer specification is unreliable because it over-fits the data: coefficients on a variable and its lag are in several instances large and opposite in sign, and the predicted desired fuel intensity show implausible oscillations over time. Therefore, we believe our base specification is the most suitable one given the short time period over which we can observe pre-CAFE behavior.

\section{Conclusion}

Our study supports many earlier findings that the long-run rebound effect, i.e. the elasticity by which changes in fuel efficiency affect the amount of driving, was $20-25 \%$ in the U.S. over the last third of the $20^{\text {th }}$ century. What is new is evidence that the rebound effect diminishes with income, and possibly increases with the fuel cost of driving. Since incomes have risen and real fuel costs have fallen, the rebound effect has declined considerably over time. For example, our results suggest it was less than half as large in the years 1997-2001 than over the entire sample. The rebound effect is likely to diminish still further as rising incomes reduce the significance of fuel costs in decisions about travel, although this may be offset to some extent by increases in fuel prices.

This result is relevant to policy. For example, the recent debate over whether to strengthen fuel-efficiency standards has emphasized the potential adverse effects on traffic congestion (e.g. Portney et al., 2003). If the rebound effect has become smaller over time, these adverse effects will be smaller than has been thought. More generally, quantity standards are relatively more attractive compared to fuel taxes if the secondary effects of the standards on other consumer decisions are small. Put differently, if most of the elasticity of fuel consumption with respect to price reflects changes in the fuel efficiency of vehicles, as our results imply, then it is easier to design standards whose effects on fuel consumption and driving are similar to those of taxes. Their effects on fuel tax revenues, of course, are still different.

Our model as estimated can be used to forecast the dynamic adjustment path resulting from specific policies. For example, in 2004 California adopted regulations, under legislation mandating reduction of greenhouse gases, that impose fuel-efficiency mandates to be phased in 
over the period 2009-2016. Because our model has a dynamic component, it could predict the year-by-year response to such a policy while taking into account projected changes in income and fuel prices - although the reliability of doing so diminishes if projected values lie outside the ranges observed in our data.

In urbanized areas, traffic congestion is an endogenous part of the system explaining reactions to changes in fuel efficiency. Presumably, any increased congestion would curtail the increased travel predicted by our model. To say how much, we would need a model of congestion formation along with a model explaining how it affects the demand for travel. Our model makes a start on this by including as variables urbanization and population relative to road supply, but a more exact link to congestion would be a desirable addition.

The degree to which the CAFE regulations have affected fleet fuel efficiency remains uncertain. It probably is bracketed by the results using our two versions of the regulatory variable named cafe-i.e. the results in Tables 4 and in Appendix Table B2. The question of CAFE's effects remains an interesting area for future research, and we believe our approach offers a better chance of resolving it than previous attempts. To make further progress probably requires estimating models that disaggregate the passenger-vehicle fleet into the two categories, cars and light trucks, that are regulated differently under CAFE. 


\section{References}

Bertrand, M., E. Duflo, and S. Mullainathan, 2004, "How Much Should We Trust Differences-in Differences Estimates?” Quarterly Journal of Economics, 199 (1), pp. 249-275.

Blair R.D., D.L. Kaserman, and R.C. Tepel, 1984, “The Impact of Improved Mileage on Gasoline Consumption,” Economic Inquiry, 22 (2), pp. 209-217.

Bunch, D.S., D. Brownstone, and T.F. Golob, 1996, "A Dynamic Forecasting System For Vehicle Markets With Clean-Fuel Vehicles," in D.A. Hensher, J. King and T.H. Oum, eds., World Transport Research: Proceedings of 7th World Conference on Transport Research, (Pergamon, Oxford) Vol. 1, pp. 189-203.

CARB, 2004, Staff Report: Initial Statement of Reasons for Proposed Rulemaking, Public Hearing to Consider Adoption of Regulations to Control Greenhouse Gas Emissions from Motor Vehicles. Sacramento: California Air Resources Board, August 6. Available at: http://www.arb.ca.gov/regact/grnhsgas/isor.pdf (accessed October 2004).

Cervero, R., and M. Hansen, 2002, "Induced Travel Demand and Induced Road investment," Journal of Transport Economics and Policy, 36 (3), pp. 469-490.

Davidson, R., and J.G. MacKinnon, 1993, Estimation and Inference in Econometrics. Oxford: Oxford Univ. Press.

De Jong G. and H. Gunn, 2001, "Recent Evidence on Car Cost and Time Elasticities of Travel Demand in Europe," Journal of Transport Economics and Policy, 35 (2), 137-160.

Fair, Ray C., 1984, Specification, Estimation, and Analysis of Macroeconometric Models. Cambridge, Mass.: Harvard Univ. Press.

Goldberg P. K., 1998, The Effects of the Corporate Average Fuel Efficiency Standards, Journal of Industrial Economics, 46 (4), 1-33.

Goodwin, P.B., 1996, "Empirical Evidence on Induced Traffic: A Review and Synthesis,'Transportation, 23 (1), pp. 35-54.

Goodwin, P., J. Dargay, and M. Hanly, 2004, "Elasticities of Road Traffic and Fuel Consumption with Respect to Price and Income: A Review," Transport Reviews, 24 (3), 275-292.

Graham D.J. and S. Glaister, 2002, The Demand for Automobile Fuel: A Survey of Elasticities, Journal of Transport Economics and Policy, 36 (1), 1-26.

Greene D.L., 1992, Vehicle Use and Fuel Economy: How Big is the Rebound Effect?, Energy Journal, 13 (1), 117-143.

Greene D.L., J.R. Kahn and R.C. Gibson, 1999, Fuel Economy Rebound Effect for US Households, Energy Journal, 20 (3), 1-31.

Greening L.A., D.L. Greene and C. Difiglio, 2000, Energy Efficiency and Consumption - The Rebound Effect - A Survey, Energy Policy, 28, 389-401.

Harrington W., 2003, Implications of CAFE for Conventional Air Pollutants and Congestion, paper presented to the American Economic Association and the Association of Environmental and Resources Economists, San Diego, Jan. 
Haughton J. and S. Sarkar, 1996, Gasoline Tax as a Corrective tax: Estimates for the United States, 1970-1991, Energy Journal, 17 (2), 103-126.

Hensher D.A., 1986, Dimensions of Automobile Demand: An Overview of an Australian Research Project, Environment and Planning A, 18, 1339-1374.

Hensher D.A., N.C. Smith, F.W. Milthorpe, and P. Barnard, 1992, Dimensions of Automobile Demand: A Longitutinal Study of Household Automobile Ownership and Use. NorthHolland, Amsterdam.

Jones C.T., 1993, Another Look at U.S. Passenger Vehicle Use and the 'Rebound' Effect from Improved Fuel Efficiency, Energy Journal, 14 (4), 99-110.

Lave, C.A., 1996, What Really Is the Growth of Vehicle Usage? Transportation Research Record, 1520, 117-121.

Mannering F.L., 1986, A Note on Endogenous Variables in Household Vehicle Utilization Equations, Transportation Research B, 20 (1), 1-6.

National Research Council, 2002, Effectiveness and Impact of Corporate Average Fuel Economy (CAFE) Standards. National Academy Press, Washington, D.C.

Parry I.W.H. and K.A. Small, 2005, Does Britain or the United States Have the Right Gasoline Tax?, American Economic Review, 95 (4), 1276-1289.

Pickrell D. and P. Schimek, 1999, Growth in Motor Vehicle Ownership and Use: Evidence from the Nationwide Personal Transportation Survey, Journal of Transportation and Statistics, 2 (1), 1-17.

Portney, P.R., I.W.H. Parry, H.K. Gruenspecht, and W. Harrington, 2003, The Economics of Fuel Economy Standards, Journal of Economic Perspectives, 17, 203-217.

Quantitative Micro Software, 2004, EViews 5 User's Guide, QMS, Irvine, Calif.

Schimek P., 1996, Gasoline and Travel Demand Models Using Time Series and Cross-Section Data from the United States, Transportation Research Record, 1558, 83-89.

Small K.A. and K. Van Dender, 2005, A Study to Evaluate the Effect of Reduced Greenhouse Gas Emissions on Vehicle Miles Traveled, Final Report for the California Air Resources Board, ARB Contract Number 02-336

Train K., 1986, Qualitative Choice Analysis: Theory, Econometrics, and an Application to Automobile Demand, MIT Press, Cambridge, Mass.

USDOE, 1979, State Energy Fuel Prices by Major Economic Sector from 1960 through 1977: Preliminary Report and Documentation. US Department of Energy, Energy Information Administration, Washington, D.C.

USDOE, 1996. Policies and Measures for Reducing Energy Related Greenhouse Gas Emissions: Lessons from Recent Literature. Report No. DOE/PO-0047, US Department of Energy, Office of Policy and International Affairs, Washington, D.C., July.

USDOE, 2003, 2003 California Gasoline Price Study: Preliminary Findings, US Department of Energy, Office of Oil and Gas, Washington D.C. 
West, S.E., 2004, Distributional Effects of Alternative Vehicle Pollution Control Policies, Journal of Public Economics, 88 (3-4), 735-757.

Wooldridge, J.M., 2002, Econometric Analysis of Cross Section and Panel Data, MIT Press, Cambridge, Mass. 


\section{Appendix A: Control Variables and Data Sources}

Control Variables in (4):

$X_{M}$ : Real personal income per capita at 1987 prices, in log form and normalized by subtracting the sample mean (inc) ${ }^{34}$ number of adults divided by public road mileage (logarithm: adults/road-mile) as a rough measure of potential congestion; ratio of total population to adults (logarithm: pop/adult) as a measure of family size; fraction of state's population living in metropolitan statistical areas, normalized by subtracting its mean in the sample (Urban); fraction of the state's population living in metropolitan statistical areas with a heavy-rail transit system (Railpop); a dummy variable to represent gasoline supply disruptions in 1974 and 1979 (D7479); and a time trend measured in years since 1966 (Trend), intended to capture changes in technology and consumer preferences that we are unable to specify quantitatively. ${ }^{35} X_{M}$ also includes two interaction variables: $p m \cdot i n c$ and pm.Urban.

$X_{V}$ : This set of variables includes inc, adults/road-mile, and Trend, already defined in $X_{M}$. In addition there are two other variables: the national interest rate for auto loans (logarithm: interest); and the ratio of licensed drivers to adults (logarithm: licences/adult).

$X_{E}$ : These variables include six of the variables in $X_{M}$, namely inc, adults/road-mile, pop/adult, Urban, Railpop, and D7479. In addition we allow for the possibility of three distinct time trends in fuel efficiency: one before the OPEC embargo (1966-1973), another between the embargo and the Iranian revolution (1974-1979), and a third after the Iranian revolution (1980-2001). The rationale is that these events changed people's perception of long-term prospects for oil supplies and therefore may have affected research and development efforts related to fuel efficiency. On the assumption that changes in technology cannot happen immediately, these variables (Trend66-73, Trend74-79, Trend80+) are specified in such a way that there is a break in the slope of the trend line but not a sudden "jump" from one

\footnotetext{
${ }^{34}$ We also tried using disposable income, which excludes taxes, to see if it changed the strong influence that we find for income on the rebound effect. The results are barely distinguishable from those presented here.

${ }^{35}$ We experimented with replacing these trends by three technology variables: vehicle volume, engine horsepower, and top speed (each in the form a fractional change in that measure since 1975, the earliest year for which we have the measure, and zero prior to 1975) plus a trend variable Techtrend equal to min $\{($ year-1975), 0\} in order to capture the effects of any earlier changes (assumed linear) in these variables. This approach did not improve the estimation.
} 
regime to another. Specifically, Trend66-73= $\operatorname{Min}($ Trend,7); Trend74-79= Max[0, $\operatorname{Min}[($ Trend-7),6] $\}$; and Trend80+ = Trend -Trend66-73 - Trend74-79.

\section{Data Sources:}

\section{Adult population}

Definition: midyear population estimate, 18 years and over

U.S. Census Bureau: http:/eire.census.gov/popest/archives/1990.php and

http://eire.census.gov/popest/data/states/ST-EST2002-ASRO-02.php

(accessed 12/03/2004). Corrected as described in text.

Corporate Average Fuel Economy Standard (Miles Per Gallon)

National Highway Traffic Safety Administration (NHTSA), CAFE

Automotive Fuel Economy Program, Annual update 2001, Table I-1.

http://www.nhtsa.dot.gov/cars/rules/cafe/FuelEconUpdates/2001/Index.html. Passenger car and light truck standard are averaged in each year using nationwide VMT as weights (see VMT source).

Consumer price index - all urban consumers

Bureau of Labor Statistics (BLS), CPI (1982-84=100). http://www.bls.gov/cpi. Note: all monetary variables (gas tax, new passenger vehicle price index, price of gasoline, personal income) are put in real 1987 dollars by first deflating by this CPI and then multiplying by the CPI in year 1987. The purpose of using 1987 is for ease in replicating Haughton and Sarkar (1996).

Highway Use of Gasoline (millions of gallons per year)

1966-1995: FHWA, Highway Statistics Summary to 1995, Table MF-226

1996-2001: FHWA, Highway Statistics, annual editions, Table MF-21

Income per capita (\$/year, 1987 dollars)

Primary measure: Personal income divided by midyear population

Personal income is from Bureau of Economic Analysis (BEA): http://www.bea.doc.gov.

Alternative measures:

(1) Disposable income per capita: Available from same web site as above, starting 1969; for 1966-68 we interpolated by assuming it bore the same ratio to per capita personal income as existed in the same state for 1969-78.

(2) Gross state product per capita: Available starting 1977; for 1966-1976 we interpolated by assuming it bore the same ratio to per capita personal income as existed in the same state for 1977-87.

Interest rate: national average interest rate for auto loans $(\%)$

Definition: average of rates for new-car loans at auto finance companies and at commercial banks.

Source: Federal Reserve System, Economic Research and Data, Federal Reserve Statistical Release G.19, "Consumer Credit": 
http://www.federalreserve.gov/releases/g19/hist/cc hist tc.html. Available starting 1971 for auto finance companies, 1972 for commercial banks. For earlier years in each series, we use the predicted values from a regression explaining that rate using a constant and Moody's AAA corporate bond interest rate, based on years 1971-2001 (finance companies) or 19722001 (commercial banks).

New Car Price Index: U.S. passenger vehicles, city average, not seasonally adjusted (1987=100) Source: Bureau of Labor Statistics web site. Note: Original index has 1982-84=100.

Number of vehicles: Number of automobiles and light trucks registered 1966-1995: FHWA, Highway Statistics Summary to 1995, Table MV-201 1996-2001: FHWA, Highway Statistics, annual editions, Table MV-1

Note: "Light trucks" include personal passenger vans, passenger minivans, utility-type vehicles, pickups, panel trucks, and delivery vans.

Price of gasoline (cents per gallon, 1987 dollars)

Data Set A: U.S. Department of Energy (USDOE 1977), Table B-1, pp. 93-94 (contains 1960-1977)

Data Set B: Energy Information Administration, State Energy Data 2000: Price and Expenditure Data, Table 5 (contains 1970-2000) 2001: Energy Information Administration, Petroleum Marketing Annual, Table A1. Note: We use Data Set B for 1970-2000, and for the earlier years we use predicted values from a regression explaining Set B values for overlapping years (1970-1977) based on a linear function of Set A values.

Public road mileage: Total length of roads in state (miles)

1966-1979: FHWA, Highway Statistics, annual editions, Table M-1

1980-1995: FHWA, Highway Statistics Summary to 1995, Table HM-220

1996-2001: FHWA, Highway Statistics, annual editions, Table HM-20

\section{Rail Transit Availability Index}

Definition: Fraction of the state's population living in metropolitan statistical areas with a subway or heavy rail transit system.

Source for existence of rail by metro area: American Public Transportation Association (APTA). http://www.apta.com

Source for population by Metropolitan Statistical Areas: Statistical Abstract of the United States, section on "Metropolitan Statistics", various years.

Note: Data are missing for years 1969, 1971, 1974, 1979, 1981, 1982, 1989; for those years we interpolate between the nearest available years.

Number of Licensed Drivers

1966-1995: FHWA, Highway Statistics Summary to 1995, Table DL-201

1996-2001: FHWA, Highway Statistics, annual editions, Table DL-1C

Some outliers in this series were replaced by values given by a fitted polynomial of degree 3 . 
Urban Road Mileage: Total municipal road distance (miles) 1966-1979: FHWA, Highway Statistics, annual editions, Table M-1 1980-1995: FHWA, Highway Statistics Summary to 1995, Table HM-220 1996-2001: FHWA, Highway Statistics, annual editions, Table HM-20

Urbanization: Share of total state population living in Metropolitan Statistical Areas (MSAs), with MSA boundaries based on December 2003 definitions. Available starting 1969; for earlier years, extrapolated from 1969-79 values assuming constant annual percentage growth rate. Source: Bureau of Economic Analysis, Regional Economic Accounts. http://www.bea.doc.gov/bea/regional/reis

Vehicle Miles Traveled (millions) 1966-1979: FHWA, Highway Statistics, annual editions, Table VM-2 1980-1995: FHWA, Highway Statistics Summary to 1885, Table VM-202 1996-2001: FHWA, Highway Statistics, annual editions, Table VM-2 


\section{Appendix B: Variable Measuring Strength of CAFE Regulation}

Base Version

We followed the following steps to create the variable cafe used in our statistical analysis.

1. We first estimate the reduced-form equation explaining fuel intensity-i.e., the empirical counterpart of the third of equation set (1)—on data only from 1966-1977, with no regulatory variable included (since there was no regulation then). This equation should in principle include all exogenous variables from all three models (including $P_{V}$ for the $V$ equation); we simplified it by dropping the variable Railpop, which seemed to have little effect in this short time series. Like our other equations, it also includes one lag of the dependent variable, and allows for fixed effects and autocorrelated errors. It does not include other endogenous variables, either current or lagged; the reason is that, unlike in an instrumental variables regression, our objective is to estimate a predictive model for what fuel intensity would have been in the absence of CAFE regulation and therefore we cannot use information about what actually happened to the endogenous variables. In theory, this equation could include any number of lagged values of independent variables, because they would be present in a complete solution of system (1) for the time path of fint; however on this very short time series it is impractical to estimate so many parameters, especially of variables that are highly correlated as current and lagged values are likely to be. For the same reason of parsimony, we included only a single time trend in this predictive equation.

We denote this equation by:

$$
\text { (fint } \left.)_{i, t}=\alpha^{f R} \text {. (fint }\right)_{i, t-1}+\beta^{f R} X_{i t}^{f R}+u_{i t}
$$

where $i$ designates a state, superscript $R$ indicates the reduced form, and $X^{f R}$ denotes the set of all exogenous variables used, including prices, as described above. The results of this estimation are shown in the first column of Table B1. The statistically significant coefficients are those of (fint $_{t-1}, D 7479$, and $p v$. The price of fuel is not statistically significant (t-statistic -1.02) but has the reasonable value of -0.021 .

2. The coefficient $\alpha^{f R}$ of the lagged dependent variable is interpreted as arising from the following partial adjustment model: 


$$
(\text { fint })_{i, t}=(\text { fint })_{i, t-1}+\gamma \cdot\left\{(\text { fint })_{i, t}^{*}-(\text { fint })_{i, t-1}\right\}+u_{i t}
$$

where $(\text { fint })_{i, t}^{*}$ denotes a long-run desired value for the logarithm of fuel intensity. That is, users basing decisions in year $t$ desire to shift the vehicle stock toward one with fuel efficiency $(\text { fint })_{i, t}^{*}$ but they can do so only part way by changing a portion $\gamma$ of the stock in that year. Thus it is natural to interpret $(\text { fint })_{i, t}^{*}$ as the target fuel efficiency for new car purchases and $\gamma$ as the fraction of the fleet that turns over each year. It is easy to see that (B.2) is the same as (B.1) if we choose $\gamma=1-\alpha$ and

$$
(\text { fint })_{i, t}^{*}=\frac{\beta^{f R} X_{i t}^{f R}}{1-\alpha^{f R}} .
$$

This value is computed for each state and each year $t$.

3. From the estimated values of (fint $)_{i, t}^{*}$, we compute the US average desired fuel intensity, averaged the same way as vehicles are averaged under CAFE regulations: namely,

$$
(\text { Fint US })_{t}^{*} \frac{\sum_{i} M_{i t} \exp \left((f i n t)_{i t}^{*}\right)}{\sum_{i} M_{i t}}
$$

where $M_{i t}$ is aggregate VMT for state $i$ in year $t$.

4. Finally, we assume CAFE is binding whenever the desired efficiency $E_{t}^{*} \equiv\left(1 /\right.$ Fint $\left.U S_{t}^{*}\right)$ is less than the minimum mandated efficiency, $\bar{E}_{t}$. The latter is computed as a weighted average of the CAFE standards for light trucks and cars, the weights being current nationwide light truck and car VMT, reduced by $16 \%$, which is an estimate of the difference between fuel efficiency achieved in real driving and that achieved on the tests used to enforce the CAFE standard (Harrington, 2003). A measure of the strength of CAFE regulation is then

$$
R_{E}=\max \left\{\frac{\bar{E}_{t}}{E_{t}^{*}}, 1\right\}
$$

or its logarithm,

$$
\text { cafe } \equiv \max \left\{\left(\bar{e}_{t}-e_{t}^{*}\right), 0\right\}
$$

where $\bar{e}_{t}=\ln \left(\bar{E}_{t}\right)$ and $e_{t}^{*}=\ln \left(E_{t}^{*}\right)$. Note this measure is nationwide, not state-specific. 


\begin{tabular}{|c|c|c|c|c|}
\hline \multirow[b]{3}{*}{ Variable } & \multicolumn{3}{|c|}{$\begin{array}{l}\text { Table B1. Fuel Intensity Equation: } \\
\text { Form for Estimating Desired Fuel Efficiency }\end{array}$} & \\
\hline & \multicolumn{2}{|c|}{$\begin{array}{c}\text { Base Version } \\
(1966-1977)\end{array}$} & \multicolumn{2}{|c|}{$\begin{array}{c}\text { Alternate Version } \\
(1966-2001)\end{array}$} \\
\hline & Coefficient & Std. Error & Coefficient & Std. Error \\
\hline fint $(t-1)$ & 0.6523 & 0.0434 & 0.8667 & 0.0148 \\
\hline $\mathrm{pf}$ & -0.0253 & 0.0204 & -0.0231 & 0.0087 \\
\hline Inc & 0.0081 & 0.0291 & -0.0152 & 0.0173 \\
\hline adults/road-m & 0.0377 & 0.0268 & -0.0002 & 0.0075 \\
\hline pop/adult & -0.1848 & 0.1626 & 0.0720 & 0.0703 \\
\hline Urban & -0.2465 & 0.2294 & -0.1265 & 0.0662 \\
\hline D7479 & -0.0212 & 0.0060 & -0.0013 & 0.0046 \\
\hline Trend & -0.0123 & 0.0027 & & \\
\hline $\mathrm{pv}$ & -0.2251 & 0.0797 & 0.0844 & 0.0246 \\
\hline Interest & 0.0294 & 0.0301 & -0.0130 & 0.0077 \\
\hline licences/adult & 0.0294 & 0.0255 & $\mathbf{0 . 0 5 3 7}$ & 0.0178 \\
\hline cafe_prelim & & & -0.0545 & 0.0150 \\
\hline constant & -0.9340 & 0.2124 & -0.4356 & 0.0704 \\
\hline Rho & -0.1374 & 0.0614 & -0.1585 & 0.0281 \\
\hline No. of observations & 17 & & 17 & \\
\hline Adjusted R-squared & 0.85 & & 0.9 & \\
\hline S.E. of regression & 0.02 & & 0.0 & \\
\hline Sum squared resid & 0.28 & & 2.7 & \\
\hline Durbin-Watson stat & 2.00 & & $1.9^{\prime}$ & \\
\hline
\end{tabular}

Note: 50 constants for individual states are not shown.

\section{Alternate Version}

For our alternate version of variable cafe, we use the variable just described, with one modification, as a preliminary variable called cafe_prelim. The modification is that we omitted the time trend (Trend in Table B1), which we found plays a dominant role in producing the generally upward slope of the desired fuel-efficiency variable shown in Figure 1 of the text. (Note that the negative sign on the coefficient of Trend in Table B1 corresponds to a negative effect of time on desired fuel intensity, hence a positive effect on desired fuel efficiency.) We interpret the effect of Trend as the result of technological changes making fuel efficiency easier 
to achieve; but there is some risk in projecting such a trend, estimated on 1966-1977 data, forward to 2001. We wanted to see if, instead of relying on Trend, we could actually estimate the full reduced-form model on the longer time period.

We accomplish this by estimating the same reduced-form model as before, but with three changes: we used the full data set, deleted Trend, and added cafe_prelim. The results are shown in the second column of Table B1. The precision of estimates is much better, and in certain ways the equation is more satisfactory: both price of fuel (pf) and CAFE regulation (cafe prelim) have statistically significant effects in the expected direction, and autocorrelation is a little smaller. Note that the coefficient of the price of new vehicles $(p v)$ now has the opposite sign; apparently this variable, which trended downward throughout the period, now takes on the job of explaining long-term trends since the Trend variable was removed. Since we have no prior belief about the sign of this coefficient, we cannot say which result is more plausible. (We also tried including three trend variables in this equation, just like in our structure model of fuel intensity; in that case cafe_prelim was also fit with a (single) trend for consistency. But the results showed clear signs of overfitting, with predicted fuel intensity displaying implausible oscillations.)

We then calculate our alternate version of desired fuel efficiency with these estimated coefficients, using Step 2 above except setting the values of variable cafe_prelim to zero (in order to represent what fuel intensity consumers and manufacturers would have chosen in the absence of pressure from CAFE regulations). The rest of the calculation proceeds as in Steps 3 and 4 above.

Table B2 compares selected results of estimating our structural model with the two versions of the cafe variable. (The first two columns repeat 3SLS results from Tables 4 and 5). The main difference is that the coefficient of $v m a+p f$, which determines how fuel price affects desired fuel efficiency, is much larger and more precisely estimated using the alternate version. The coefficient of cafe is also larger, but not as precisely estimated. The fuel intensity equation fits a little better using the alternate version of cafe, according to the adjusted R-squared value. Despite these improvements, we remain concerned that with our alternate calculation procedure, our estimates of desired fuel efficiency are not robust to adding trend variables in the reducedform equation itself. In the end, we can offer no judgment about which version of cafe better depicts the tightness of regulations as perceived by market participants. 
Table B2. Comparison of Selected Structural Estimates: 3SLS

\begin{tabular}{|c|c|c|c|c|}
\hline \multirow[b]{2}{*}{ Variable } & \multicolumn{2}{|c|}{ Using Base Version of cafe } & \multicolumn{2}{|c|}{ Using Alternate Version of cafe } \\
\hline & Coefficient & Stndrd. Error & Coefficient & Stndrd. Error \\
\hline \multicolumn{5}{|c|}{ Vehicle-Miles Traveled Equation (Table 2) } \\
\hline $\operatorname{vma}(\mathrm{t}-1)$ & 0.7907 & 0.0128 & 0.8081 & 0.0127 \\
\hline $\mathrm{pm}$ & -0.0452 & 0.0048 & -0.0445 & 0.0048 \\
\hline $\mathrm{pm}^{\wedge} 2$ & -0.0104 & 0.0068 & -0.0074 & 0.0069 \\
\hline pm*inc & 0.0582 & 0.0145 & 0.0560 & 0.0148 \\
\hline pm*Urban & 0.0255 & 0.0106 & 0.0289 & 0.0108 \\
\hline inc & 0.1111 & 0.0141 & 0.1048 & 0.0142 \\
\hline Urban & -0.0548 & 0.0202 & -0.0531 & 0.0203 \\
\hline Adjusted R-squared & \multicolumn{2}{|c|}{0.9801} & \multicolumn{2}{|c|}{0.9801} \\
\hline \multicolumn{5}{|c|}{ Fuel Intensity Equation (Table 4) } \\
\hline $\operatorname{tint}(t-1)$ & 0.8158 & 0.015/ & 0.80/5 & U.U154 \\
\hline $\mathrm{vma}+\mathrm{pf}$ & -0.0460 & 0.0069 & -0.0813 & 0.0099 \\
\hline cafe & -0.1011 & 0.0115 & -0.1368 & 0.0219 \\
\hline inc & 0.0025 & 0.0163 & 0.0267 & 0.0165 \\
\hline pop/adult & -0.0111 & 0.0691 & 0.1061 & 0.0699 \\
\hline Urban & -0.1500 & 0.0522 & -0.1600 & 0.0537 \\
\hline D7479 & -0.0105 & 0.0045 & -0.0015 & 0.0044 \\
\hline Trend66-73 & 0.0006 & 0.0010 & 0.0006 & 0.0010 \\
\hline Trend74-79 & -0.0024 & 0.0010 & -0.0012 & 0.0011 \\
\hline Trend80+ & -0.0037 & 0.0004 & -0.0029 & 0.0004 \\
\hline constant & -0.1137 & 0.0809 & 0.1520 & 0.0974 \\
\hline rho & -0.1353 & 0.0236 & -0.1121 & 0.0245 \\
\hline Adjusted R-squared & \multicolumn{2}{|c|}{0.9604} & \multicolumn{2}{|c|}{0.9615} \\
\hline
\end{tabular}

Rebound Effect and Other Price Elasticities

\begin{tabular}{lcccc}
\multicolumn{1}{c}{ Elasticity } & Short Run & Long Run & Short Run & Long Run \\
\hline $\begin{array}{l}\text { Elasticity of VMT with respect to } \\
\text { fuel cost per mile: (a) }\end{array}$ & & & & \\
At sample average & -0.0452 & -0.2221 & -0.0446 & -0.2398 \\
& $(0.0048)$ & $(0.0238)$ & $(0.0048)$ & $(0.0262)$ \\
At US 1997-2001 avg. (b) & -0.0216 & -0.1066 & -0.0242 & -0.1308 \\
& $(0.0090)$ & $(0.0433)$ & $(0.0091)$ & $(0.0474)$ \\
At US 1997-2001 avg. ex- & -0.0311 & -0.1531 & -0.0310 & -0.1671 \\
cept $p f=\$ 1.93$ nominal (c) & $(0.0060)$ & $(0.0299)$ & $(0.0060)$ & $(0.0329)$ \\
\hline $\begin{array}{l}\text { Elasticity of fuel intensity } \\
\text { with respect to fuel price: }\end{array}$ & & & & \\
At sample average & -0.0440 & -0.2047 & -0.0780 & -0.3595 \\
& $(0.0067)$ & $(0.0338)$ & $(0.0097)$ & $(0.0444)$ \\
\hline $\begin{array}{l}\text { Elasticity of fuel consumption } \\
\text { with respect to fuel price: }\end{array}$ & & & & \\
At sample average & -0.0873 & -0.3813 & -0.1191 & -0.5131 \\
At US 1997-2001 avg. (b) & -0.0657 & -0.3097 & -0.1018 & -0.4697 \\
$\begin{array}{l}\text { At US 1997-2001 avg. ex- } \\
\text { cept } p f=\$ 1.93 \text { nominal (c) }\end{array}$ & -0.0744 & -0.3380 & -0.1075 & -0.4837 \\
\hline
\end{tabular}

Notes: See Tables 2-5. Not all coefficients are listed here. 


\section{Appendix C: Results of Model with Fuel Price and Fuel Intensity Entered Separately}

\begin{tabular}{|c|c|c|c|c|c|c|}
\hline \multirow[b]{2}{*}{ Variable } & \multicolumn{2}{|c|}{ Estimated Using 3SLS } & \multicolumn{2}{|c|}{ Estimated Using 2SLS } & \multicolumn{2}{|c|}{ Estimated Using OLS } \\
\hline & Coeff. & Std. Err. & Coeff. & Std. Err. & Coeff. & Std. Err. \\
\hline \multicolumn{7}{|c|}{ Vehicle-Miles Traveled Equation } \\
\hline $\operatorname{vma}(\mathrm{t}-1)$ & 0.8108 & 0.0142 & 0.8144 & 0.0174 & 0.0428 & 0.0184 \\
\hline $\mathrm{pf}$ & -0.0560 & 0.0053 & -0.0532 & 0.0057 & -0.0856 & 0.0067 \\
\hline $\mathrm{p} f^{*}$ (inc) & 0.0968 & 0.0225 & 0.1374 & 0.0314 & 0.1679 & 0.0323 \\
\hline pf*(Urban) & 0.0487 & 0.0262 & 0.0307 & 0.0357 & -0.0203 & 0.0331 \\
\hline fint & 0.0081 & 0.0142 & -0.0006 & 0.0162 & -0.5847 & 0.0151 \\
\hline fint*(inc) & 0.0548 & 0.0507 & 0.0251 & 0.0614 & 0.3492 & 0.0565 \\
\hline fint*(Urban) & -0.0799 & 0.0554 & -0.0151 & 0.0700 & -0.1235 & 0.0575 \\
\hline inc & 0.0826 & 0.0159 & 0.0886 & 0.0177 & 0.3660 & 0.0239 \\
\hline D7479 & -0.0465 & 0.0037 & -0.0463 & 0.0039 & -0.0136 & 0.0020 \\
\hline Trend & 0.0009 & 0.0004 & 0.0008 & 0.0005 & 0.0000 & 0.0007 \\
\hline rho & -0.0973 & 0.0230 & -0.0596 & 0.0289 & 0.8128 & 0.0139 \\
\hline \multicolumn{7}{|c|}{ Fuel Intensity Equation } \\
\hline fint $(\mathrm{t}-1)$ & 0.7962 & 0.0146 & 0.8236 & 0.0156 & 0.7869 & 0.0163 \\
\hline $\mathrm{pf}+\mathrm{vma}$ & -0.0406 & 0.0073 & -0.0374 & 0.0076 & -0.0940 & 0.0075 \\
\hline cafe & -0.0916 & 0.0119 & -0.0672 & 0.0141 & -0.1025 & 0.0144 \\
\hline inc & 0.0094 & 0.0166 & 0.0130 & 0.0170 & 0.0076 & 0.0174 \\
\hline D7479 & -0.0096 & 0.0045 & -0.0069 & 0.0047 & -0.0057 & 0.0046 \\
\hline Trend74-79 & -0.0022 & 0.0011 & -0.0030 & 0.0012 & 0.0009 & 0.0012 \\
\hline Trend80+ & -0.0039 & 0.0005 & -0.0031 & 0.0005 & -0.0046 & 0.0005 \\
\hline rho & -0.1379 & 0.0236 & -0.1408 & 0.0287 & -0.0955 & 0.0293 \\
\hline
\end{tabular}

